\title{
1 Asymmetric dynamical behavior of thermochemical \\ 2 plumes and implications for Hawaiian lava \\ 3 composition
}

4 Maxim D. Ballmer*1, Garrett Ito ${ }^{1}$, and Cheng Cheng $^{2}$

5
(1) School of Ocean and Earth Sciences and Technology, University of Hawaii at Manoa, 1680 East-West Road, Honolulu, HI 96822, USA. (2) Dept. Earth and Planetary Sciences, University of California, 307 McCone Hall, Berkeley, CA 94720, USA. (*) corresponding author: ballmer@hawaii.edu

\begin{abstract}
The Hawaiian Kea and Loa volcano trends have commonly been interpreted as directly reflecting a compositional zonation within the Hawaiian plume stem, inherited from the lowermost mantle. As this zonation is often associated with variations in mafic material, and as such materials, especially eclogites, impact mantle flow, this study aims to characterize the ascent and melting of bilaterally-zoned thermochemical plumes. Our geodynamic models predict that plumes bearing $\gtrsim 12 \%$ eclogite tend to stagnate as a deep eclogitic pool (DEP) in the midupper mantle where phase changes lead to a maximum in eclogite excess density. This behavior can explain recent seismic-tomography results, and predicts thermal asymmetry of material rising out of the DEP to feed the hotspot. Thermal asymmetry is caused by the effects of ambient-mantle flow or plume-stem zonation on DEP dynamics, and ultimately boosts peridotite melting on the melting zone's hotter side. This hotter side is hence less dominated by melting of mafic materials, despite being fed by equally or more such materials than the cooler side. These results suggest that the Kea side of the Hawaiian Plume is equally or more eclogitic than the Loa side, opposite to previous interpretations. Care should thus be taken in mapping geographical variations in lava chemistry into the deep mantle.
\end{abstract}

\section{Introduction}

Better constraints on the make-up of the deep mantle are needed to advance our understanding of the differentiation and secular evolution of our planet (cf. Boyet and Carlson, 2005; Labrosse et al., 2007). In the framework of mantle plume theory, hotspot lavas provide one of the most important means of probing the composition of the deep mantle. For example, the global-scale DUPAL anomaly among hotspot lavas (Dupre and Allegre, 1983) has been associated with the seismically imaged large low shear-wave velocity provinces (LLSVPs) (Castillo et al., 1998; Wen et al., 2001; Wen, 2006). These LLSVPs are compositionally dense 
structures in the deep mantle (Ishii and Tromp, 1999; Masters et al., 2000; Mosca et al., 2012), from the margins of which most mantle plumes are inferred to rise (Burke and Torsvik, 2004; 2006; Torsvik et al., 2010). Regional geographical variations in ocean-island basalt geochemistry have also been interpreted as reflecting lower-mantle compositional heterogeneity in the Pacific (e.g., Konter et al., 2008).

Similarly, local-scale geographical variations of lava geochemistry within single hotspot chains, such as within the Marquesas, Society and Samoa chains, are interpreted as reflecting heterogeneity in the deep mantle (Workman et al., 2004; Huang et al., 2011; Chauvel et al., 2012; Payne et al., 2013). Another example that has recently attracted a great deal of interest is the bilateral geochemical asymmetry of Hawaiian volcanism (Fig. 1). The Hawaiian Islands have long been interpreted to be a double chain of volcanoes (Jackson et al., 1972), of which the prevalent morphological trends, the southwestern "Loa" and the northeastern "Kea" trend, display distinct geochemical signatures (Frey and Rhodes, 1993; Kurz et al., 1996; Abouchami et al., 2005; Weis et al., 2011). This distinction has been interpreted as revealing a bilateral compositional zonation of the deep plume conduit (e.g., Abouchami et al., 2005). Huang et al. (2011) and Weis et al. (2011) argue that the Hawaiian Plume - as apparently rising from the margin of a LLSVP — entrains compositionally distinct materials into either sides of the plume stem.

The possibility that entrainment of distinct materials may be expressed in hotspot-lava composition requires that plumes rise with little lateral material exchange or rotation across their conduits (about a vertical axis). In classical theory, plumes are described as upwellings that rise near-vertically through the entire mantle to support magmatism, purely driven by thermal buoyancy (Morgan, 1972; Griffiths and Campbell, 1990; Sleep, 1990; Ribe and Christensen, 1994). Based on such purely thermal plume models (i.e., with density being independent of composition), Farnetani and Hofmann $(2009 ; 2010)$ demonstrate that patterns of deep-mantle composition can indeed be directly reflected by geographic variations in hotspot-lava geochemistry. However, the Hawaiian Plume is thought to carry compositionally dense, mafic materials (e.g., entrained from the LLSVP or a slab graveyard), thereby potentially behaving more complexly than a classical plume (e.g., Farnetani and Samuel, 2005), particularly if these materials are initially distributed non-uniformly, or even bilaterally asymmetrically, within the deep part of the plume stem.

Evidence for the presence of mafic materials (e.g., pyroxenite or eclogite) in the source of Hawaiian lavas comes from major-element, trace-element, as well as isotopic data (Hauri, 1996; Huang and Frey, 2005; Sobolev et al., 2005 , 2007; Huang et al., 2007; Herzberg, 2011; Jackson et al., 2012; Pietruszka et al., 2013). These materials are inferred to be more abundant in the source of Loa, than of Kea volcanoes, and are likely to contribute to the geochemical distinction between the two trends (Sobolev et al., 2005; Greene et al., 2010; Jackson et al., 2012). 
Eclogites are significantly denser than peridotites and thus strongly affect plume ascent. Analogue and numerical geodynamic models show that such eclogitic or "thermochemical" plumes display asymmetric and time-dependent behavior (Davaille, 1999; Farnetani and Samuel, 2005; Lin and van Keken, 2005; Kumagai et al., 2008), much in contrast to classical-plume behavior - which so far has inspired the interpretations of geochemical asymmetry of Hawaiian lavas. This complex behavior is caused by the competition between diffusive, positive thermal buoyancy and non-diffusive, negative compositional buoyancy in thermochemical plumes. Phase transitions can account for additional complications (e.g., Farnetani and Samuel, 2005). For example, Ballmer et al. (2013) show that a peak in the excess density of eclogite relative to peridotite due to phase changes in the olivine and quartz systems (Aoki and Takahashi, 2004) can cause thermochemical (i.e., eclogitic) plumes to pool in a broad layer at $300 \sim 410 \mathrm{~km}$ depth (“deep eclogitic pool", DEP) before rising to feed the hotspot (Fig. 2).

Evidence for such complex dynamical behavior beneath the Hawaiian hotspot is provided by recent seismic tomography. Body-wave tomography, based on data collected during the regional Plume and Lithosphere Undersea Melt Experiment (PLUME), images a thick ( 400 km), asymmetric body of slow seismic velocities beneath the hotspot (Wolfe et al., 2009, 2011). These seismic models disagree with classical plume theory, which predicts a much thinner $(<100 \mathrm{~km})$ and symmetric layer ("pancake") to pond beneath the lithosphere. The presence of a large volumes of low-velocity materials is further supported by a recent joint inversion of body waves, surface waves, and ambient noise recorded by PLUME (Cheng et al., this volume). In addition to body-wave tomography alone, these joint inversions resolve two layers of seismically slow material in the upper mantle: one beneath the lithosphere (at $\sim 100 \mathrm{~km} \mathrm{depth}$ ), and another one contained in the depth range of $\sim 250 \mathrm{~km}$ to $\sim 450 \mathrm{~km}$ (Fig. 3; Cheng et al.'s (this volume)). Seismic resolution tests indicate that these seismic constraints are consistent with the presence of a double-layered (DEP and pancake) thermochemical plume beneath Hawaiian hotspot (Ballmer et al., 2013; Cheng et al., this volume).

In this study, we explore the dynamics of bilaterally asymmetric thermochemical plumes in which one side of the plume carries a higher fraction of compositionally dense materials (such as eclogite) than the other side. By predicting geographical patterns of volcanism due to the melting of mafic and ultramafic source lithologies, we investigate the link between the deep compositional zonation and geographical variations in lava composition. Our results show that thermochemical plume dynamics in the upper mantle can create geographical patterns of lava composition independent of a zonation in the deep plume conduit. They can veil, or even apparently reverse, any deep bilateral zonation.

\section{Methods and model description}


We use a Cartesian version of the finite-element code Citcom (Moresi et al., 1996) to model thermochemical-plume dynamics. The model domain of length $5280 \mathrm{~km}$ ( $x$-direction), width $3300 \mathrm{~km}$ (y-direction), and height $660 \mathrm{~km}$ (z-direction) is discretized in $768 \times 512 \times 96$ finite elements with the smallest elements (i.e., $4.5 \times 4.5 \times 4.5 \mathrm{~km}$ ) located in the asthenosphere near the hotspot. This fine resolution is needed to accurately model melting processes and predict magma compositions. A horizontal velocity in the $x$-direction of $v_{\text {plate }}=80 \mathrm{~km} / \mathrm{Myr}$ is imposed at the top boundary to simulate Pacific plate motion. All boundaries, except for the front $(x=0)$ and back sides $(x=5280 \mathrm{~km})$ are closed to in- and outflow. At a distance of $3135 \mathrm{~km}$ from the front side (i.e., inflow boundary), $2145 \mathrm{~km}$ from the back side (i.e., outflow boundary), and $1650 \mathrm{~km}$ from both lateral side boundaries, a Gaussian thermal anomaly of half-width $r_{P}$ (see Table 1) and amplitude of $+300 \mathrm{~K}$ is imposed to supply a plume at the base of the model. Upward flow of plume material into the model domain (i.e., from the lower, into the upper mantle) is only allowed within a radius of $4.8 r_{P}$ from the plume center, where the bottom boundary is locally open to vertical flow.

In the core of the plume, a cylinder of radius $r_{E}$ is taken to contain eclogite (Fig. 4). The radius of this cylinder $r_{E}=1.2 r_{P}$ in most models, except for case $\mathrm{S} 2$, in which $r_{E}=100 \mathrm{~km} \approx$ $1.33 r_{P}$ (cf. Table 1). The imposed initial volume percent of eclogite within the cylinder is $\Phi_{E C L, S W}$ on the southwestern (SW) side of the plume and $\Phi_{E C L, N E}$ on the northeastern (NE) side, both varied for different models between $8 \%$ and $16 \%$ (cf. Fig. 4). With plate motion parallel to the $x$ direction, the $y$-direction is NE-SW. In symmetric cases S1-S2, the imposed distribution of eclogite is uniform $\left(\Phi_{E C L, S W}=\Phi_{E C L, N E}\right.$, Fig. 4). For the other models (cases Z1-Z5), a compositional bilateral zonation in the deep plume stem is simulated by imposing $\Phi_{E C L, S W}>$ $\Phi_{E C L, N E}$. This aspect of our model setup is novel compared to any thermochemical plume study to date, including Ballmer et al. (2013). We note that the end-member situations of purely axisymmetric (S1-S2) versus bilaterally asymmetric (Z1-Z5) compositional structure are idealizations of what is probably more complex in reality.

In contrast to the eclogitic core $\left(r \leq r_{E}\right)$ of the plume, the relatively cool plume outskirts $(r>$ $r_{E}$ ) with excess temperatures $<\sim 110 \mathrm{~K}$ (case S2: $<\sim 87 \mathrm{~K}$ ), as well as the cooler ambient mantle contain no eclogite. Both the plume and the ambient mantle are dominated by peridotitic lithologies: they initially contain $\Phi_{H P}=20 \%$ hydrous peridotite in addition to the percentage $\Phi_{D P}$ $=\left(100 \%-\Phi_{H P}-\Phi_{E C L, S W}\right)$ of dry peridotite. The remainder of the mantle consists of a refractory lithology that does not melt beneath the hotspot (cf. Stracke et al., 2011). Accordingly, the initial volume fraction of the refractory lithology is $\Phi_{R L}=\Phi_{E C L, S W}$ in the ambient mantle, $\Phi_{R L}=0 \%$ on the SW side of the deep plume stem, and $\Phi_{R L}=\Phi_{E C L, S W}-\Phi_{E C L, N E}$ on the NE side. Composition is advected with the flow, evolves due to melting and hybridization (see next paragraph) and is steadily replenished (and set to initial conditions) where material enters the model domain at the front side of the model box and the base of the plume.

Including eclogite in the models impacts the results both through the associated variations in the mantle density due to solid phase changes and melting (Fig. 2), as well as the expression of 
mafic material in the magmas. To account for the effects of phases changes in the quartz and olivine systems, the excess density of eclogite relative to peridotite is defined to be $220 \mathrm{~kg} / \mathrm{m}^{3}$ in the depth range 300 to $410 \mathrm{~km}$, and $110 \mathrm{~kg} / \mathrm{m}^{3}$ elsewhere, based on the laboratory experimental results of Aoki and Takahashi (2004). For eclogite melting, we use Yasuda et al. 's (1994) empirically-derived parameterization. As such, the models predict eclogite to begin melting first at a depth of $\sim 260 \mathrm{~km}$ and continue to melt to a maximum allowable extent of $60 \%$ at a depth of $\sim 150 \mathrm{~km}$ within the hottest core of the plume (Sobolev et al., 2005; 2011). We assume that once any eclogitic melt is formed, it instantaneously reacts with the ambient peridotite in a 1-to-1 fashion to form bimineralic, olivine-free pyroxenite (Yaxley and Green, 1998; Sobolev et al., 2005; 2007; Herzberg, 2011). In the hotspot melting zone at about 110-200 km depth, both peridotite and pyroxenite melt, and do so according to the parameterizations of Hirschmann (2000) and Pertermann and Hirschmann (2003), respectively. Further details of the melting parameterization, as well as of the mantle density and rheology treatments are reported in the Appendix. Model parameters are listed in Table 2.

Following Ballmer et al. (2010, 2011; 2013), the predicted volumetric fraction $X_{P X}$ of pyroxenite-derived to the total (i.e., pyroxenite + peridotite derived) volume of volcanism is the quantity used to characterize lava composition. This quantity is computed by assuming all magmas rise vertically and mix perfectly before reaching the surface. To predict the average composition of shield-stage volcanism on the SW and NE sides of the hotspot (i.e., $X_{P X, S W}$ and $X_{P X, N E}$, respectively), we integrate over two adjacent, rectangular strips on the surface. Each strip is $80 \mathrm{~km}$ long in the $x$-direction (i.e., parallel to plate motion) and $63.4 \mathrm{~km}$ wide in the $y$ direction, thus the total width (in $y$ ) of the rectangular zone, from which extracted magmas are focused to form the double volcano chain, is $126.8 \mathrm{~km}$. To capture main shield-stage volcanism (of duration $\tau_{\text {shield }} \approx 1 \mathrm{Myr}$ ) along the two (i.e., Kea and Loa) volcano trends the two strips (of length $80 \mathrm{~km}=\tau_{\text {shield }} / v_{\text {plate }}$ ) are positioned to maximize the total volcanic flux between them with similar fluxes from each strip. Accordingly, the boundary between the two strips nearly bisects the absolute peak in vertical magma flux from below, and defines the central axis of the model hotspot chain. It is this axis that is used to define bilateral symmetry or asymmetry of plume parameters and volcanism.

\section{Results}

The models are relevant to the Hawaiian hotspot in that their predictions are consistent with key observations. In all our models (cf. Table 1), a hot mantle plume rises through the upper mantle to support localized hotspot (i.e., shield-stage) volcanism, focused over an area $\sim 100 \mathrm{~km}$ long and $\sim 75 \mathrm{~km}$ wide - consistent with geological constraints. The plume thermal anomaly imposed at the base of the model of $+300 \mathrm{~K}$ agrees well with chemical geothermometry (Herzberg et al., 2007). From case to case, the predicted average volcanic flux varies between $\sim 130,000 \mathrm{~km}^{3} / \mathrm{Myr}$ and $\sim 190,000 \mathrm{~km}^{3} / \mathrm{Myr}$ (or $\sim 4.1 \mathrm{~m}^{3} / \mathrm{s}$ and $\sim 6.0 \mathrm{~m}^{3} / \mathrm{s}$, see Table 3 ), a range 
that is within that of published measurements (van Ark and Lin, 2004; Vidal and Bonneville, 2004; Robinson and Eakins, 2006). The modeled plumes also dynamically push up the plate to support hotspot swells of heights $870 \mathrm{~m} \leq h_{\text {swell }} \leq 960 \mathrm{~m}$ and widths $1130 \mathrm{~km} \leq w_{\text {swell }} \leq 1340 \mathrm{~km}$ - similar to observations (Wessel, 1993; Crosby and McKenzie, 2009) (also see arch-shaped region of shallow seafloor around Hawaii in Fig. 1). As the amount of mafic materials carried by the plume varies from case to case, we modulate plume radius to maintain good agreement with these key hotspot characteristics (Table 1).

One result common to all of the models is that mafic lithologies heavily contribute to hotspot volcanism. Any eclogite carried by the plume, of which the initial contents in our models vary between $8 \%$ and $16 \%$ from case to case (and from side to side of the plume), melts to a maximum degree of $60 \%$ in the depth range of about $150-260 \mathrm{~km}$ to react with ambient peridotite (in a 1:1 fashion) and to form pyroxenite (Yaxley and Green, 1998; Sobolev et al., 2005 ; 2007). The resulting moderate fractions of pyroxenite (i.e., 9.6\%-19.2\% of the mantle) dominate magmatism, contributing $X_{P X}>50 \%\left(66 \%<X_{P X}<83 \%\right)$ to the model hotspot lavas, even though the source consists mainly of peridotite (with volume fractions of $74.4 \%-87.2 \%$ ). This dominance is caused by the much higher isobaric melt productivities in pyroxenite than in peridotite, and reinforced by consumption of latent heat by the first at the expense of the latter (Phipps Morgan, 2001; Katz and Rudge, 2011). While such a dominance of melting mafic materials at the Hawaiian hotspot is indeed supported by many recent studies (Hauri, 1996; Huang and Frey, 2005; Sobolev et al., 2005 , 2007; Huang et al., 2007; Herzberg, 2011; Jackson et al., 2012; Pietruszka et al., 2013), other studies favor a dominance of peridotitic melting (cf. Putirka et al., 2011). We also note that our predictions in terms of $X_{P X}$ are upper bounds, as incomplete wall-rock reactions in the deep eclogite melting zone can produce mafic lithologies with lower productivities than simulated in this study (e.g. websterites instead of pyroxenites (Mallik and Dasgupta, 2012)).

\subsection{Double layering of plume material in the upper mantle}

The presence of dense eclogite leads to thermochemical plumes that are wider and rise more sluggishly compared to non-eclogitic (i.e., thermal or "classical") plumes with similar thermal buoyancy fluxes. Moreover, the doubling of the excess density of eclogite in the depth range of 300 to $410 \mathrm{~km}$ due to the effects of phase transitions in the quartz and olivine systems (Aoki and Takahashi, 2004) can profoundly modify plume morphologies and upwelling dynamics (cf. Ballmer et al., 2013). If enough eclogite is present in the deep plume conduit (see below) the rise of the plume partially stalls in this depth range to form a layer of hot material hundreds of $\mathrm{km}$ wide and $\sim 150 \mathrm{~km}$ thick (Fig. 5), which we refer to as the deep eclogitic pool (DEP).

For example, in cases S1-S2, the eclogitic plume core (originally $15 \%$ eclogite) has a net (i.e., thermal plus compositional) buoyancy of $-3.3 \mathrm{~kg} / \mathrm{m}^{3}$ to about $-23 \mathrm{~kg} / \mathrm{m}^{3}$ within the critical 
221 depth range of 410-300 km, imaged as the blue region in Figs. 5b,e (buoyancy is defined as the 222 density deficit relative to the ambient mantle at the reference temperature). Accordingly, this

223

224

225

226

227

228

229

230

231

232

233

234

235

236

237

238

239

240

241

242

243

244

245

246

247

248

249

250

251

252

253

254

255

256

257

258

259 material tends to sink back down into the transition zone. However, it is supported from below by the deep plume conduit (red colors at the bottom of Figs. 5b,e), which in the transition zone is almost entirely positively buoyant (i.e., by up to $\sim 13.2 \mathrm{~kg} / \mathrm{m}^{3}$ ), and is sustained on its sides by the non-eclogitic plume outskirts (with a buoyancy of up to $+10 \mathrm{~kg} / \mathrm{m}^{3}$; red sheath around the blue DEP in Figs. 5b,c,e,f). Therefore, the eclogitic core spreads laterally (but not indefinitely) to form a wide DEP (Figs. 5a-f). As material continues to feed the DEP from below, the DEP inflates to cross the $300 \mathrm{~km}$-deep coesite-stishovite phase transition, where the material instantaneously regains a positive net buoyancy (Figs. 5c,f). The resulting increase in upwelling rate above this phase transition sets up a local minimum in dynamic pressure that guides the (not necessarily vertical) rise of material through the DEP. This local minimum is enhanced by the consumption of eclogite due to melting, occurring in the depth range of about $150-260 \mathrm{~km}$. This process strongly enhances the net buoyancy. Consequently, the shallow plume conduit is narrower and rises more rapidly (by rates of up to $\sim 1 \mathrm{~m} / \mathrm{yr}$ ) than the deep plume stem, and ponds beneath the lithosphere as a thin $(<100 \mathrm{~km})$ pancake that supports the hotspot swell.

Similarly, compositionally-zoned cases Z3-Z5 with average eclogite contents $>12 \%$ display a strong double layering of plume material with a wide DEP (Figs. 5m-u). In these cases, material from the more eclogite-rich, SW sides of the plumes primarily inflates the DEP as shown in Figs. 6d-f by contours of initial eclogite content (i.e., eclogite content with any modifications due to melting removed). The materials from the eclogite-poor NE sides of the plumes instead rise relatively rapidly through, and contribute relatively little volume to the DEP, as they largely remain positively buoyant (by up to $+3.3 \mathrm{~kg} / \mathrm{m}^{3}$ (case Z3) and $+7.7 \mathrm{~kg} / \mathrm{m}^{3}$ (case Z5)).

In contrast, in compositionally-zoned cases Z1-Z2 with average eclogite contents $<12 \%$, most of the plume-core material remains positively or near-neutrally buoyant even in the depth range of 300-410 $\mathrm{km}$. The plumes therefore rise without stalling significantly to form a DEP (Figs. 5g-1). Just a portion of the cooler outer plume core in case Z2, particularly on the SW side, becomes marginally negatively buoyant, leading to only a slight $(\sim 50 \%)$ widening of the plume conduit in the mid upper mantle (Fig. 5k). The plume dynamics in cases Z1 and Z2 are indeed much like that of a classical thermal plume (Figs. 5g-1).

In summary, average initial plume-core eclogite contents $>12 \%$ appear to be required to form a DEP in plumes with parameters that are realistic for the Hawaiian Plume (see above). As the dynamical behavior is governed by the competition of thermal and compositional buoyancy forces, smaller such contents would be required for other plumes with smaller excess temperatures (Herzberg et al., 2007). For example, a content of $>6 \%$ is likely to be sufficient to induce formation of a DEP for a perhaps more common plume with a peak excess temperature of $\sim 150 \mathrm{~K}$. The estimated critical eclogite contents would have to be slightly corrected upward (by $\sim 3 \%$ ) if the ambient mantle itself contained eclogite $(\sim 3 \%)$, as is indicated by studies of midocean ridge basalts that suggest a content of $\sim 5 \%$ pyroxenite in the upper mantle (Hirschmann 
and Stolper, 1996). Considering this possibility, the eclogite contents modeled here can be regarded as excess contents relative to the ambient mantle.

\subsection{Asymmetry in plume behavior and melting}

Our models not only display complex and asymmetric structures at the depths of the DEP (i.e., 410-300 km), but also above this depth range (Fig. 6). These asymmetries are seen in the overall morphology of the plume as a whole, as well as in the temperatures and eclogite contents across the shallow plume conduit and plume pancake (section 3.2.1). The structure of temperature and initial eclogite content (i.e., eclogite content imposed in the deep plume stem) within the melting zone are then found to produce bilateral asymmetries in the mafic contribution to volcanism (section 3.2.2). Despite these asymmetries, the current models generally reproduce the main results of purely thermal plume models (Farnetani and Hofmann, 2009; 2010; Farnetani et al., 2012) that materials originating from distinct sides of the deep plume stem mostly remain on their sides all the way to the surface (evident in contours of initial eclogite content, Fig. 6). However, the added effects of compositional buoyancy as well as melting behavior of peridotitic vs. mafic material in our models lead to different conclusions about the relationship between magma and source compositions.

\subsubsection{Thermochemical-plume dynamics, temperature, and composition}

In case Z3, strong asymmetry in temperature rises out of a compositionally-zoned deep plume stem and DEP (Fig. 6). The higher imposed eclogite content on the SW versus the NE side of the deep plume core $\left(\Phi_{E C L, S W}=15 \%, \Phi_{E C L, N E}=12 \%\right)$ leads to a higher average excess density on the SW side, a density contrast that doubles in the depth range of $300-410 \mathrm{~km}$ where the DEP forms. This situation has three important consequences: First, the NE side of the DEP (with a near-neutral average buoyancy of about $-0.9 \mathrm{~kg} / \mathrm{m}^{3}$ ) is preferentially entrained into the shallow plume, whereas the SW side of the DEP (with a strongly negative average buoyancy of about $-9.7 \mathrm{~kg} / \mathrm{m}^{3}$ ) displays more extensive pooling and lateral spreading (see contours in Fig. 6d). Second, the more eclogitic material from the SW side of the deep plume stem, fills over half of the DEP (imaged as broad orange-to-yellow area in Fig. $7 \mathrm{~m}$ ), pushing the less eclogitic material as well as the whole shallow plume conduit to the NE (dashed-dotted line in Fig. 6d is symmetry axis of the model setup for reference). Third, the less hot, outer plume-core material from the SW side of the deep plume stem fails to rise through the depth range of $300-410 \mathrm{~km}$ (green colors on the right-hand side of Fig. 6d; dark blue colors Figs. 5n-o). Therefore, the materials that enter the shallow plume from the (initially more eclogitic) SW side are, on average, hotter than those on the (initially less eclogitic) NE side. The variations in initial eclogite content in the DEP thus create a "thermal filter" for the temperatures entering the shallow plume. The resulting thermal asymmetry in the shallow plume conduit is visualized in 
Figure 7 (m-o) as an offset between the peak in temperature (bull's eye of dark grey contours; black cross) and the focus in mantle upwelling (bull's eye of red contours; red cross). As the focus of upwelling lies very close to the peak hotspot volcanic flux, which defines the hotspot location, case Z3 predicts bilateral asymmetry with higher temperatures on the SW side of the hotspot melting zone (green and black dashed lines encircle the pyroxenite + peridotite melting zone in Fig. 6d with colors highlighting the thermal asymmetry).

Increasing the contrast in initial eclogite contents of the deep plume stem (from case Z3 to cases Z4 and Z5) boosts the asymmetry in the make-up and temperature distribution of the shallow plume conduit. The modeled plumes in cases Z4 and Z5 carry average eclogite contents (Table 1) that are similar to those of case Z3, and therefore generally behave similarly to that in case Z3. However, they display greater cross-chain variations in initial eclogite contents (Table 1). As the thermal-filter effect is greater, the proportion of the less eclogitic (NE) relative to the more eclogitic (SW) material within, as well as the thermal asymmetry across the shallow plume conduit increase from cases Z3 to Z4, and Z4 to Z5 (preponderance of green and blue colors increases from Fig. $7 \mathrm{o}$ to Fig. $7 \mathrm{r}$ to Fig. $7 \mathrm{u}$ ). The asymmetry of the overall morphology of the plume also increases with greater initial eclogite contrast (Figs. $5 \mathrm{~m}-5 \mathrm{u}$ ), as the less eclogitic, NE material, which predominantly feeds the shallow plume, is pushed increasingly to the margins of the DEP (Fig. 7). Accordingly, the offset between the peak temperature and the peak upwelling rate increases from cases $\mathrm{Z} 3(\sim 15 \mathrm{~km})$ to $\mathrm{Z} 5(\sim 40 \mathrm{~km})$.

In contrast to cases Z3-Z5, cases Z1-Z2 do not display significant thermal asymmetry of the shallow plume (Fig. 7) despite a deep-rooted compositional asymmetry that differs only slightly from that in case Z3 (In cases Z1, Z2 and Z3, $\Phi_{E C L, S W}$ equals 1.25 $\Phi_{E C L, N E}, 1.2 \Phi_{E C L, N E}$, and $1.25 \Phi_{E C L, N E}$, respectively; cf. Fig. 4). The main cause for the lack of the asymmetry is the lack of a large DEP in cases Z1 and Z2. Accordingly, plume material rises rapidly through the depth range of 300-410 km, the thermal filter effect (as discussed above for cases Z3-Z5) is negligible, and any thermal asymmetry of the shallow plume conduit relative to the peak upwelling rate (and hence hotspot center) is minimal (Fig. 7).

For a non-zoned plume, any thermal asymmetry across the shallow plume conduit would have to be explained by entirely different mechanisms than those described above, as the makeup of the deep plume stem in these cases is axisymmetric (with $15 \%$ eclogite throughout the plume core). While case S1 displays only very minor thermal asymmetry of the shallow plume, case S2 displays strong asymmetry - both across the DEP and the shallow plume (Figs. 5-7). In both cases, the DEP is strongly negatively buoyant (average buoyancy is about $-10 \mathrm{~kg} / \mathrm{m}^{3}$, cf. Table 1) and is again prevented from sinking down into the lower mantle by the rise of the deep plume stem from below (and is contained laterally by the non-eclogitic plume outskirts rising around its sides). Such a quasi-stable DEP is sensitive to ambient-mantle flow such as that induced by sublithospheric small-scale convection (Ballmer et al., 2007; 2011) or ambient mantle wind (cf. Steinberger and Antretter, 2006). In the current calculations, a sublithospheric downwelling interacts with the plume pancake and leans down on the NE side of the DEP (Figs. 
5 and 6). In case S1, this downwelling is insufficient to induce strong dynamical asymmetry within the DEP, as the DEP is well supported from the sides by a relatively thick and buoyant layer of plume-outskirt material (Figs. 5b,c). In case S2, the sublithospheric downwelling is instead sufficient to displace the whole DEP and to cause the shallow plume conduit to rise offcenter (i.e., from the DEP on the side opposite to the downwelling), as the supporting layer of plume-outskirt material is thinner and less buoyant (Figs. 5e,f). Such an off-center rise (i.e., shifted to the SW) causes an asymmetric temperature distribution in the shallow plume with higher temperatures on its NE side. That said, the thermal gradient across the shallow plume in case S2 is opposite to that in cases Z3-Z5 (i.e., with higher temperatures on the SW side). We note however that the SW and NE directions are conventions of our model setup defined by the distribution of eclogite in the deep plume stem (with $\Phi_{E C L, S W} \geq \Phi_{E C L, N E}$ ), and that models S1 and S2 with $\Phi_{E C L, S W}=\Phi_{E C L, N E}$ may be mirrored about the central plane at $y=1650$ (mirrored cases Z1-Z5 would have $\left.\Phi_{E C L, S W}<\Phi_{E C L, N E}\right)$.

The temperature distribution across the shallow plume in case S2 is not only asymmetric, but is also time-dependent (Figs. 6g-h). Such time-dependence is related to episodic extraction of hot material out of the DEP. Any extraction tends to increase the net density of the DEP. In case S2, this increase is sufficient to cause the DEP to spread laterally and sink slightly, a process that chokes the flux of material through the DEP's roof. Once outflow is smaller than inflow from below, the DEP re-inflates, until it is thick enough for material to rise above the coesitestishovite phase transition at $300 \mathrm{~km}$ depth to generate another shallow-plume pulse (also see Movie S3 in Ballmer et al., 2013). The process begins again, and resulting shallow-plume pulsations provide a dynamical explanation for the variations in total volcanic flux documented along the Hawaii-Emperor chain (van Ark and Lin, 2004; Vidal and Bonneville, 2004; Ballmer et al., 2013). In addition, the location of the shallow plume meanders relative to the DEP creating a time-dependence of the average temperature and thermal asymmetry across the shallow plume conduit. In cases S1 and Z1-Z5 instead, the DEP is sufficiently well supported by plume-outskirt material (due to small $r_{E}$ ) to balance inflow and outflow. Thus, an increase of the eclogitic plume core's radius, $r_{E}$ from 90 to $100 \mathrm{~km}$ controls the regime shift between the pseudo-steady case S1 and strongly time-dependent case S2 (cf. Ballmer et al., 2013). Accordingly, we expect that double-layered, compositionally-zoned plumes with $r_{E} \approx 100 \mathrm{~km}$ also display shallow-plume pulsations.

\subsubsection{Melting dynamics and its expression in volcanism}

In our models, a combination of thermal asymmetry across the melting zone and compositional zonation of the plume conduit gives rise to geographical variations in hotspot-lava composition. In cases $\mathrm{Z} 1-\mathrm{Z} 2$, temperatures across the melting zone are only minimally asymmetric, therefore, the source composition advected from the deep plume stem predominantly controls magma make-up. Accordingly, the contribution of pyroxenitic lavas in 
volcanism $X_{P X}$ is higher on the SW side of the hotspot as it overlies higher eclogite contents in the plume stem (Figs. 8c-d, Table 3). This prediction agrees with the traditional explanation for geographical variations in lava composition, particularly for the Hawaiian Kea and Loa trends (Abouchami et al., 2005; Farnetani and Hofmann, 2009; 2010; Huang et al., 2011; Weis et al., 2011; Farnetani et al., 2012). However, cases Z1 and Z2 suffer from a key weakness: the plumes do not develop a broad DEP, and thus cannot explain the seismic structure imaged by the PLUME regional seismic tomography (see next section).

The relationship between magma and plume-stem make-up differ for the compositionallyzoned cases which do produce a DEP (Z3-Z5). These are the cases with strong thermal asymmetry in the shallow plume (see section 3.2.1), and results show that peridotite melting starts deeper (Figs. 6d-6h) and reaches higher degrees on the hotter side of the shallow plume conduit than on its cooler side. The effect of thermal asymmetry on pyroxenite melting is much smaller, as pyroxenite reaches maximum degrees of melting on both sides. These melting dynamics systematically reduce $X_{P X}$ on the hotter (and more eclogitic) SW side of the hotspot (Figs. 8e-g), and accordingly trade off with the effects of source composition in terms of $X_{P X}$.

In case $\mathrm{Z4}$, for example, the shallow thermal asymmetry consequently leads to a more-or-less symmetric distribution of $X_{P X}$ across the main melting zone thus completely obscuring the bilateral asymmetry in the composition of the plume conduit (Fig. 8f, Table 3). In cases Z3 and $Z 5$, the effect of thermal asymmetry on melting dynamics even reverses the sense of bilateral asymmetry in magma composition compared to the plume's compositional zonation (Figs. 8e,g). In case $\mathrm{Z3}$, the average $X_{P X}$ is greater on the NE side with $X_{P X, S W}-X_{P X, N W}=-1.2 \%$ despite the fact that it is the SW side of the plume that contains more eclogite initially $\left(\Phi_{E C L, S W}-\Phi_{E C L, N E}=\right.$ $+3 \%)$. Case Z5 predicts an even greater reversal in asymmetry at the surface $\left(X_{P X, S W}-X_{P X, N E} \approx-\right.$ $9 \%$, although it has the strongest bilateral asymmetry in the deep conduit $\left(\Phi_{E C L, S W}-\Phi_{E C L, N E}=\right.$ $+6 \%$ ) of the cases modeled. Thus, the thermal asymmetry of the material feeding the melting zone can be as important or even more important than the zonation in the deep plume stem in controlling the geographic patterns of $X_{P X}$.

In fact, thermal asymmetry alone can give rise to geographic variations in lava composition even without any compositional zoning in the deep plume stem (Ballmer et al., 2013). In case S2, both $X_{P X, S W}(\sim 83.4 \%$ to $\sim 91.5 \%)$ and $X_{P X, N E}(\sim 79.0 \%$ to $\sim 90.8 \%)$ strongly vary over model time (Figs. 8h-j; Table 3), both due to temporal variations in the flux of and lateral variations in temperature within the shallow plume conduit (Figs. 6g-h; also see last paragraph of section 3.2.1). Although the initial eclogite content in case $\mathrm{S} 2$ remains constant across the plume core, $X_{P X}$ generally remains lower on the (hotter) NE side of the hotspot than the (cooler) SW side, except for a very few snapshots with near-symmetric $X_{P X}$, one of which is shown in Figure $8 \mathrm{~h}$. The difference in average $X_{P X}$ between the two sides (i.e., $X_{P X, S W}-X_{P X, N E \text { ) }}$ ranges between $\sim 0.6 \%$ and $\sim 6.8 \%$. Case S1 with near-symmetric temperatures in the shallow plume instead does not display significant asymmetry in $X_{P X}$ across the hotspot (Fig. 8a, Table 3). 


\section{$\underline{3.3 \text { Implications of seismic constraints on plume dynamics }}$}

To compare our model predictions with geophysical constraints from seismic tomography, we compute three-dimensional models of synthetic seismic shear-wave velocity from our geodynamic simulations. Synthetic seismic velocities are calculated from the temperatures, densities and eclogite contents predicted from our simulations. We use the method of Faul and Jackson (2005) to do this computation (for parameters used, see Ballmer et al., 2013), and account for the effects of eclogite content on seismic velocities according to $X u$ et al. (2008). For comparison, we also predict a synthetic seismic velocity model for a purely thermal plume (i.e., based on the reference model of Ballmer et al. (2011)).

Figure 9 shows horizontal cross-sections through the synthetic velocity models at $350 \mathrm{~km}$ depth, and elucidates that the models fall into two categories: first, models with a wide body of seismically slow material in the mid upper mantle (cases S1-S2, Z3-Z5) due to the presence of a DEP; second, models without such a wide low-velocity body (cases Z1-Z2), similar to the reference thermal (i.e., classical) plume model (Fig. 9a). Only plumes from the first category are able to stabilize large volumes of seismically slow material in the upper mantle. We note that Figure 9 shows a forward model of synthetic seismic velocities, unfiltered by the inversion process. Seismic filtering (i.e., by a resolution test) would instead be required to directly compare these velocity models to seismic tomography images, particularly for vertical cross-sections (not shown in Figure 9), in which biases of the inversion process (such as smearing) are expected to be most strongly expressed.

Using the inversion matrix of the shear-wave tomography model of Wolfe et al. (2009), Ballmer et al. (2013) performed such seismic resolution tests for case S1 (Fig. 9b) and the reference thermal plume model (Fig. 9a), representative cases for the first and second (with and without DEP) categories, respectively. These tests demonstrated that the double layering of plume material as in our case S1 (i.e., analogous to their case A) is expected to be imaged as one thick $(\sim 400 \mathrm{~km})$ and wide $(\sim 500 \mathrm{~km})$ body of low velocities (due to vertical smearing), much like what shear-wave tomography imaged beneath Hawaii (Wolfe et al., 2009). They further showed that our case S1 can provide a much better explanation for the station-averaged, shearwave arrival times measured during the seismic PLUME experiment than the reference thermal plume model (originally from Ballmer et al. (2011)). Accordingly, manifestation of a DEP beneath the Hawaiian hotspot such as in cases S1-S2 and Z3-Z5 is demanded by the seismic constraints.

This interpretation is supported by joint inversion of surface-wave, shear-wave and ambientnoise data collected during PLUME. Such a joint inversion (Fig. 3; Cheng et al. (this volume)) resolves more detailed structure within the large body of low velocities retrieved from shearwave tomography alone (Wolfe et al., 2009). It suggests the presence of two distinct layers of seismically slow material at the predicted depths of the DEP and plume pancake. This 
450

451

452

453

454

455

456

457

458

459

460

461

462

463

464

465

466

467

468

469

470

471

472

473

474

475

476

477

478

479

480

481

482

483

484

485

486

geophysical evidence points toward a thermochemical plume beneath Hawaii much like those portrayed in this study (i.e., in cases S1-S2, Z3-Z5), and away from a more classical plume without a DEP (cases Z1-Z2).

On a more detailed level, the predictions of the subset of our models with a DEP also appear to be in good agreement with the specific structures resolved by joint tomography. In terms of its lateral extent, the predicted body of seismically slow material (i.e. DEP) in a subset of our models (especially, S1, S2, Z3-Z5) is consistent with observations (dashed ellipses in Fig. 9 and 3e), albeit displaced eastward. The presence of short-wavelength, seismically fast structure within the DEP, as predicted by cases S2 and Z5 (Figs. 9c, 9h), is also generally consistent with observations (cf. Fig. 3e). These first-order agreements between predictions of simplified geodynamic models and geophysical constraints are indeed encouraging.

\section{Discussion}

In our geodynamic study, we find three different scenarios for geographic variations in the materials melting beneath the hotspot: (1) Cases without a DEP (Z1 and Z2) predict a direct geometrical relationship between the geographic pattern of mafic content in volcanism $\left(X_{P X}\right)$ and the zonation of the deep plume conduit, similar to the traditional explanation for the geochemical differences between the Loa and Kea trends (Abouchami et al., 2005; Farnetani and Hofmann, 2009; 2010; Huang et al., 2011; Weis et al., 2011; Farnetani et al., 2012). (2) In contrast, compositionally-zoned cases with a DEP (cases Z3-Z5) predict a non-intuitive relationship, as thermal asymmetry across the shallow plume conduit boosts peridotite melting on the more eclogitic side to veil (Z4) or even reverse (Z3 and Z5) the asymmetry of mafic materials in volcanism. (3) Finally, thermal asymmetry is sufficient to generate a geographic asymmetry in $X_{P X}$ even for non-zoned plumes (case $\mathrm{S} 2$ ).

Of these three scenarios, only scenarios 2 and 3, which include a DEP, are applicable to Hawaii. Only they can account for the stabilization of large volumes of hot, seismically slow material in the mid upper mantle, as is indicated by the PLUME tomography results (cf. Wolfe et al., 2009; Ballmer et al., 2013). Thus, shallow thermal asymmetry rising out of the DEP (as in scenarios 2 and 3) appears to be as or more important than a deep compositional zonation of the plume (as only in scenario 2) in giving rise to the geochemical difference between the Hawaiian Kea and Loa trends. In both scenarios 2 and 3, the low- $X_{P X}$ side of the melting zone is predicted to be hotter (thus peridotite melts to higher extents) than the high- $X_{P X}$ side. As Kea-type lavas are thought to be influenced less by mafic melting than Loa-type lavas (i.e., $X_{P X, S W}>X_{P X, N E}$ (Sobolev et al., 2005; Greene et al., 2010; Herzberg, 2011; Jackson et al., 2012)), we infer that the Kea side of the mantle melting zone is hotter than the Loa side (cf. Xu et al., in press). Accordingly, the distinction between the Kea and Loa trends can either arise out of a non-zoned Hawaiian Plume (scenario 3) (cf. Ballmer et al., 2011; 2013), or a zoned plume with greater eclogite 
contents on the low- $X_{P X}$ Kea side of the deep plume stem (scenario 2) - not on the high- $X_{P X}$ Loa side as previously inferred (e.g., Sobolev et al., 2005). In either case, the model results in combination with the seismic evidence, argue against a direct geographic link between Loa and Kea lava geochemistry and the composition of the SW and NE sides of the deep plume stem (cf. Abouchami et al., 2005; Farnetani and Hofmann, 2010; Huang et al., 2011; Weis et al., 2011).

Future studies should be designed to distinguish between scenarios 2 and 3, and hence to test whether the deep Hawaiian Plume is indeed compositionally zoned. Thermal asymmetry across the melting zone is greater in scenario 2 than in scenario 3, and greatest in the cases with the strongest contrast in initial plume eclogite content (i.e., case Z5 in this study). Differences in temperature between the two sides control variations in the maximum extent of peridotite melting across the hotspot, which should be testable using major elements and various traceelements. The challenge here will be to distinguish the contributions from mafic versus peridotitic melting, which are expected to be sensitive to temperature themselves. Such a test will hence likely require a combination of geodynamic modeling with targeted geochemical analysis. Geophysical evidence may be able to provide complementary constraints on the amplitude of asymmetry in temperature across the melting zone (cf. Rychert et al., 2013), and thus ultimately on that in eclogite content across the plume stem.

Constraining the make-up of the plume stem feeding into the DEP will serve to improve our understanding of the behavior of the plume in the lower-mantle. Geodynamic models have predicted complex thermochemical plume dynamics for a range of compositions involving plume pulsations on timescales of $10 \mathrm{~s}$ of Myr, or longer (e.g., Lin and van Keken, 2005; Kumagai et al., 2008). Such pulsations would be superimposed on mid-term pulsations rising out of the DEP itself such as predicted by our study (e.g., case S2). These long-term and mid-term pulsations ultimately act to modulate the compositions and temperatures across the melting zone, and are thus able to address the time-evolution of the Loa/Kea geochemical asymmetry, which may (Sinton et al., in review) or may not (e.g., Abouchami et al., 2005) persist up the chain beyond the Molokai Fracture Zone (cf. Fig. 1). We also note that there is no direct evidence for or against the existence of a DEP beneath the Hawaiian hotspot 10s of Myr ago. While crustal thickness variations along the Hawaii-Emperors (van Ark and Lin, 2004; Vidal and Bonneville, 2004) on timescales that are consistent with DEP pulsations may be taken as indirect evidence (cf. Ballmer et al., 2013), future geodynamic studies should assess the long-term stability of a DEP, especially with strongly time-dependent plume behavior in the lower mantle feeding into the DEP.

Resolving the dynamics and melting of the Hawaiian Plume in space and time is indeed needed to improve our understanding of the mantle as a whole. For example, it may provide insight into the compositions of the materials making up the deep lower mantle, as well as the dynamical processes by which the Hawaiian Plume may or may not entrain LLSVP material (cf. Steinberger and Torsvik, 2012). Studying other plumes in addition to the Hawaiian Plume may provide constraints on the heat and material fluxes across the mantle, as well as the possible 
origins of the LLSVPs. However, our results suggest that high-resolution seismic images of these other plumes would be required to assess the origin of any local-scale geographic variations in lava geochemistry across the related hospots.

\section{Conclusions}

In this study, we examine the upper-mantle dynamics of mantle flow and melting of thermochemical plumes with a bilateral zonation in the content of mafic materials rising out of the lower mantle. The predictions of our geodynamic simulations can be grouped within three different scenarios:

(1) Thermochemical plumes with a bilateral asymmetry in eclogite content, and average such contents of $<12 \%$, behave similar to classical thermal plumes with little mixing between the two sides of the plume and a direct relationship between source and lava composition, consistent with previous findings (Farnetani and Hofmann, 2009; 2010). However, these plumes cannot account for the stabilization of large volumes of hot material in the mid upper mantle, as is evident for the Hawaiian Plume by seismic tomography.

(2) In contrast, compositionally-zoned plumes with average eclogite contents of $>12 \%$ intermittently stagnate in the depth range of about $300-410 \mathrm{~km}$ to form a deep eclogitic pool (DEP), and hence can reconcile seismic constraints. This pooling is due to a relative density maximum of eclogite at these depths, which in turn only allows the hottest material to enter the shallow plume on the more eclogitic side of the plume. The resulting thermal asymmetry across the melting zone gives rise to more vigorous peridotite melting on the initially more eclogitic side, therefore reducing the expression of mafic materials in volcanism $X_{P X}$ to the point that it is similar to or even lower than on the other (i.e., initially less eclogitic) side.

(3) Moreover, compositionally non-zoned plumes that rise asymmetrically out of a DEP (e.g., due to ambient mantle flow) can also sustain a thermal gradient across the melting zone, and thus geographic variations in $X_{P X}$ across the hotspot.

These model predictions (i.e., scenarios 2 and 3) have important implications for Hawaiian Plume dynamics and the composition of the deep mantle. Asymmetry in $X_{P X}$ across the hotspot, as evident by the geochemical distinction between the Kea and Loa trends (e.g., Sobolev et al., 2005), is not necessarily an explicit indication of a (bilateral) compositional zonation of the deep plume stem, but rather of a thermal gradient across the hotspot melting zone with higher temperatures on the Kea side. If a zonation in the content of mafic materials indeed exists, our results suggest that it is the NE Kea side of the deep plume stem that contains more eclogite than the SW Loa side, contrary to previous interpretations. Our findings put into question previous efforts of mapping the deep mantle from geographical variations in hotspot lava composition. 
563 Table 1: Key plume parameters and average densities of the plume core for all cases. Radii of 564 the plume's thermal and compositional anomalies $\left(r_{P}\right.$ and $\left.r_{E}\right)$ as well as initial eclogite contents 565 on either side of the plume $\left(\Phi_{E C L, N E}\right.$ and $\left.\Phi_{E C L, S W}\right)$ are given. Positive and negative net buoyancies 566 refer to plume-core material being less and more dense than the ambient non-plume mantle, 567 respectively. Cases S1 and S2 (*) are analogous to cases A and B in Ballmer et al. (2013), 568 respectively.

\begin{tabular}{|c|c|c|c|c|c|c|}
\hline & \multirow[t]{2}{*}{$\boldsymbol{r}_{P}$} & \multirow[t]{2}{*}{$\boldsymbol{r}_{\boldsymbol{E}}$} & \multirow[t]{2}{*}{$\overline{\Phi_{E C L, N E}}$} & \multirow[t]{2}{*}{$\Phi_{E C L, S W}$} & \multicolumn{2}{|c|}{ average plume-core net buoyancy } \\
\hline & & & & & at $300-410 \mathrm{~km}$ depth & elsewhere \\
\hline case $\mathrm{S1}{ }^{*}$ & $75 \mathrm{~km}$ & $90 \mathrm{~km}$ & $15 \%$ & $15 \%$ & $-9.7 \mathrm{~kg} / \mathrm{m}^{3}$ & $6.8 \mathrm{~kg} / \mathrm{m}^{3}$ \\
\hline case $\mathrm{S}^{*} *$ & $75 \mathrm{~km}$ & $100 \mathrm{~km}$ & $15 \%$ & $15 \%$ & $-10.7 \mathrm{~kg} / \mathrm{m}^{3}$ & $5.8 \mathrm{~kg} / \mathrm{m}^{3}$ \\
\hline case $\mathrm{Z1}$ & $65 \mathrm{~km}$ & $78 \mathrm{~km}$ & $8 \%$ & $10 \%$ & $3.5 \mathrm{~kg} / \mathrm{m}^{3}$ & $13.4 \mathrm{~kg} / \mathrm{m}^{3}$ \\
\hline case $\mathbf{Z 2}$ & $70 \mathrm{~km}$ & $84 \mathrm{~km}$ & $10 \%$ & $12 \%$ & $-0.9 \mathrm{~kg} / \mathrm{m}^{3}$ & $11.2 \mathrm{~kg} / \mathrm{m}^{3}$ \\
\hline case $\mathbf{Z 3}$ & $75 \mathrm{~km}$ & $90 \mathrm{~km}$ & $12 \%$ & $15 \%$ & $-6.4 \mathrm{~kg} / \mathrm{m}^{3}$ & $8.4 \mathrm{~kg} / \mathrm{m}^{3}$ \\
\hline case $\mathrm{Z4}$ & $70 \mathrm{~km}$ & $84 \mathrm{~km}$ & $11 \%$ & $15 \%$ & $-5.3 \mathrm{~kg} / \mathrm{m}^{3}$ & $9.0 \mathrm{~kg} / \mathrm{m}^{3}$ \\
\hline case $\mathrm{Z5}$ & $75 \mathrm{~km}$ & $90 \mathrm{~km}$ & $10 \%$ & $16 \%$ & $-5.3 \mathrm{~kg} / \mathrm{m}^{3}$ & $9.0 \mathrm{~kg} / \mathrm{m}^{3}$ \\
\hline
\end{tabular}


572 Table 2: notations. ${ }^{\mathrm{a}}$ Hirth and Kohlstedt (1996, 2003); ${ }^{\mathrm{b}}$ Karato and Wu (1993), ${ }^{\mathrm{c}}$ Hirth 573 (2002), , ${ }^{\mathrm{d}}$ Kohlstedt and Zimmerman (1996); (§) see Appendix 7.2.

\begin{tabular}{|c|c|c|}
\hline Parameter & Symbol & Value \\
\hline reference ambient mantle temperature & $T_{m}$ & $1350^{\circ} \mathrm{C}$ \\
\hline plume peak thermal anomaly & $\Delta T_{\text {plume }}$ & $300 \mathrm{~K}$ \\
\hline adiabatic gradient & $\gamma$ & $0.3 \mathrm{~K} / \mathrm{km}$ \\
\hline heat capacity & $c_{P}$ & $1250 \mathrm{~J} \cdot \mathrm{kg}^{-1} \cdot \mathrm{K}^{-1}$ \\
\hline thermal diffusivity & $\kappa$ & $10^{-6} \mathrm{~m}^{2} / \mathrm{s}$ \\
\hline thermal expansivity & $\alpha$ & $3 \cdot 10^{-5} \mathrm{~K}^{-1}$ \\
\hline latent heat of melt & $L$ & $560 \mathrm{~kJ} / \mathrm{kg}$ \\
\hline critical porosity in peridotite & $\varphi_{C}$ & $0.4 \%$ \\
\hline critical porosity in pyroxenite & $\varphi_{C, P Y X}$ & $10 \%$ \\
\hline residual porosity in peridotite & $\varphi_{R}$ & $0.4 \%$ \\
\hline residual porosity in pyroxenite & $\varphi_{R, P Y X}$ & $5 \%$ \\
\hline water partitioning coefficient & $D_{H 2 O}$ & 0.01 \\
\hline bulk water content in the ambient mantle & $c_{0}$ & $310.64 \mathrm{ppm}$ \\
\hline water content below which peridotite behaves like dry peridotite ${ }^{a}$ & $c_{d r y}$ & $6 \mathrm{ppm}$ \\
\hline effective mantle viscosity & $\eta_{\text {eff }}$ & $1.6 \cdot 10^{19} \mathrm{~Pa} \cdot \mathrm{s}$ \\
\hline activation energy & $E^{*}$ & $300 \mathrm{~kJ} / \mathrm{mol}$ \\
\hline activation volume & $V^{*}$ & $5 \cdot 10^{-6} \mathrm{~m}^{3} / \mathrm{mol}$ \\
\hline dehydration stiffening coefficient $^{\mathrm{a}}$ & $\xi$ & 100 \\
\hline melt lubrication exponent $^{\mathrm{d}}$ & $\zeta$ & -40 \\
\hline mantle density & $\rho_{0}$ & $3300 \mathrm{~kg} / \mathrm{m}^{3}$ \\
\hline excess density of eclogite & $\Delta \rho_{E C L}$ & $110-220 \mathrm{~kg} / \mathrm{m}^{3} \S$ \\
\hline density change with depletion in peridotite & $\Delta \rho_{F}$ & $-165 \mathrm{~kg} / \mathrm{m}^{3}$ \\
\hline magma density & $\rho_{M}$ & $2800 \mathrm{~kg} / \mathrm{m}^{3}$ \\
\hline depth of the box & $D$ & $660 \mathrm{~km}$ \\
\hline top velocity boundary condition & $v_{\text {plate }}$ & $80 \mathrm{~km} / \mathrm{Myr}$ \\
\hline gravity acceleration & $G$ & $9.8 \mathrm{~m} / \mathrm{s}^{2}$ \\
\hline ideal gas constant & $R$ & $8.314 \mathrm{Jmol}^{-1} \mathrm{~K}^{-1}$ \\
\hline
\end{tabular}


575

576

577

578

579

580

\section{1}

582

583

584

585

586

587

588

589

590

591

592

593

594

595

596

597

598

599

Table 3: Key model predictions for all cases. Swell height $h_{\text {swell }}$; swell width $w_{\text {swell }}$; contribution of mafic lavas in volcanism on the southwestern and northeastern sides of the hotspot, $X_{P X, S W}$ and $X_{P X, N E}$. (§) Volcanic fluxes reported are average total volcanic fluxes including secondary volcanism occurring well away from the hotspot. (*) In case S2, the reported key model predictions strongly vary over model time; the reported values are averages with standard deviations reported in brackets.

\begin{tabular}{|l|l|l|l|l|l|l|}
\hline & $\boldsymbol{h}_{\text {swell }}$ & $\boldsymbol{w}_{\text {swell }}$ & volcanic flux $\boldsymbol{X}$ & $\boldsymbol{X}_{\boldsymbol{P X}, \boldsymbol{S W}}$ & $\boldsymbol{X}_{\boldsymbol{P X}, \boldsymbol{N E}}$ & $\boldsymbol{X}_{\boldsymbol{P X}, \boldsymbol{S W}}-\boldsymbol{X}_{\boldsymbol{P X}, \boldsymbol{N E}}$ \\
\hline case S1 & $920 \mathrm{~m}$ & $1200 \mathrm{~km}$ & $5.4 \mathrm{~m}^{3} / \mathrm{s}$ & $83.56 \%$ & $82.71 \%$ & $0.85 \%$ \\
\hline case S2* & $732 \mathrm{~m}$ & $1100 \mathrm{~km}$ & $3.4 \mathrm{~m}^{3} / \mathrm{s}$ & $87.77 \%$ & $83.55 \%$ & $4.22 \%$ \\
& $(65 \mathrm{~m})$ & $(31 \mathrm{~km})$ & $\left(0.6 \mathrm{~m}^{3} / \mathrm{s}\right)$ & $(1.93 \%)$ & $(2.34 \%)$ & $(1.55 \%)$ \\
\hline case Z1 & $870 \mathrm{~m}$ & $1130 \mathrm{~km}$ & $4.1 \mathrm{~m}^{3} / \mathrm{s}$ & $70.49 \%$ & $65.25 \%$ & $5.24 \%$ \\
\hline case Z2 & $940 \mathrm{~m}$ & $1200 \mathrm{~km}$ & $6.0 \mathrm{~m}^{3} / \mathrm{s}$ & $76.22 \%$ & $73.54 \%$ & $-2.68 \%$ \\
\hline case Z3 & $940 \mathrm{~m}$ & $1290 \mathrm{~km}$ & $6.5 \mathrm{~m}^{3} / \mathrm{s}$ & $81.32 \%$ & $82.52 \%$ & $-1.20 \%$ \\
\hline case Z4 & $890 \mathrm{~m}$ & $1190 \mathrm{~km}$ & $5.5 \mathrm{~m}^{3} / \mathrm{s}$ & $66.08 \%$ & $66.10 \%$ & $-0.02 \%$ \\
\hline case Z5 & $960 \mathrm{~m}$ & $1340 \mathrm{~km}$ & $5.6 \mathrm{~m}^{3} / \mathrm{s}$ & $70.09 \%$ & $79.04 \%$ & $-8.95 \%$ \\
\hline
\end{tabular}

\section{Figure captions}

Fig. 1: Mapview of Hawaiian volcanism and bathymetry. Red and blue triangles denote sites of Kea-type and Loa-type shield-stage lavas (distinguished by their ${ }^{208} \mathrm{~Pb}^{*} /{ }^{206} \mathrm{~Pb}^{*}$ compositions (Weis et al., 2011)), respectively. Classifications of Waianae and Kaena-ridge volcanoes are based on Sinton et al. (in review). Yellow triangles mark volcanoes that straddle the dividing line in ${ }^{208} \mathrm{~Pb}^{*} /{ }^{206} \mathrm{~Pb}^{*}$ as defined by Abouchami et al. (2005).

Fig. 2: Conceptual figure (not to scale) of a double-layered, thermochemical plume. The peak in excess density of eclogite relative to pyrolite (and also relative to peridotite; see left panel as reproduced from Aoki and Takahashi (2004)) can induce stagnation of a thermochemical plume to as a deep eclogitic pool (DEP) in the depth range of $\sim 300 \mathrm{~km}$ to $\sim 410 \mathrm{~km}$. Such a DEP, in combination with the shallow thermal pancake ponding beneath the lithosphere, place a large volume of hot and seismically slow material in the upper mantle, which is required by seismic tomography. The reduction of negative compositional density due to the coesite-stishovite phase transition at $\sim 300 \mathrm{~km}$ depth, as well as due to eclogite melting starting at $\sim 250 \mathrm{~km}$ depth pull eclogitic material out of the DEP in a positive-feedback mechanism. 
601 Fig. 3: Cross-sections through the seismic model HW13-SVJ of Cheng et al. (this volume)

602

603

604

605

606

607

608

609

610

611

612

613

614

615

616

617

618

619

620

621

622

623

624

625

626

627

628

629

630

631

632

633

634

635

636

637

produced from a joint inversion of shear-wave and surface-wave (teleseismic as well as ambient noise) travel times. The location of the vertical cross-sections in panels (a) and (c) are denoted in the insets in panels (b) and (d) as red lines, respectively (with red and green dots as geographical markers). Black triangles in (b) and (d) show the seismic network used for the inversion. The blue dashed line in (c) approximately separates the Kea and Loa volcano subchains. (e) The horizontal cross-section is located at the same depth $(350 \mathrm{~km})$ as the cross-sections through the synthetics shown in Figure 9. Ray coverage is highest within the thin black dashed lines (cf. Fig. 6 in Cheng et al. (this volume)). A wide body of slow shear-wave velocities at typical DEP depths is segmented by fast structure toward the west, and is surrounded by the pink dashed ellipse. The seismic images show complex structure, crudely consistent with (a) a double-layered plume in the upper mantle and a slanted stem rooted in the lower mantle, (c) a shallow plume that is asymmetric about any axis parallel to plate motion, and (e) a DEP with relatively complex structure. Panels (a) through (d) are reproduced from Cheng et al. (this volume) after minor modifications.

Fig. 4: Imposed eclogite content at the base of the deep plume stem for all cases. The eclogite bearing core of the plume is colored black to dark grey, and the surrounding non-eclogitic, but still warm outskirt of the plume stem is light grey. Eclogite contents on the two sides of the plume core are labelled. Circles are contours of imposed potential temperature from $1375{ }^{\circ} \mathrm{C}$ (outside, black) to $1625{ }^{\circ} \mathrm{C}$ (inside, white) in $25^{\circ} \mathrm{C}$ increments. In each model, the center of the plume at the base of the box is at $x=3135 \mathrm{~km}$ and $y=1650 \mathrm{~km}$. The black arrow in the top-left corner points northward.

Fig. 5: Temperature, melting, and net buoyancy of all cases (rows as annotated). Left column shows perspective view from below of potential temperature (colors) with the 1550 and $1620^{\circ} \mathrm{C}$ isosurfaces shown in translucent white and solid white, respectively. Grey and black isosurfaces denote sites of minor and major magma generation, respectively. Middle and right columns show cross-sections of net buoyancy (colored) perpendicular to plate motion. Net buoyancy is the sum of thermal and compositional contributions, expressed as density deficit relative to the ambient mantle at the reference potential temperature. Dashed-dotted lines mark the symmetry axis of the model's initial and boundary conditions. Middle column (h-n) shows cross-sections through the hottest part of the deep plume conduit and DEP. Right column shows cross-sections, slightly further downstream, through the hottest part of the shallow plume conduit (i.e., close to the peak hotspot melt production). Contours denote potential temperature in $50{ }^{\circ} \mathrm{C}$ increments with the $1500{ }^{\circ} \mathrm{C}$ isotherm dashed. Disk insets schematically show the initial distribution of eclogite, similar to Fig. 4. 
639 Fig. 6: Vertical cross-sections oriented perpendicular to plate motion of potential temperature 640 (colors), initial eclogite content (white-to-black solid contours, see legend in upper right corner) 641 and shape of the melting zone (dashed green contours for pyroxenite, dashed black for peridotite) 642 for all cases. The initial eclogite content is the original content at the position of the material at 643 the base of the model box, from where it has been advected (i.e., with the effects of eclogite 644 melting removed). As shown by the solid contours running more-or-less vertically along the 645 plume axis in the compositionally-zoned cases Z1-Z5, the two sides of the plume to not 646 physically mix with each other. In cases S2 and Z3-Z5, temperatures across the melting zones 647 are asymmetric in this cross-section, and the degrees of peridotite melting are higher (not shown) 648 and the depth of the solidi (of both lithologies but of peridotitic lithologies in particular) are 649 deeper on the hotter side of the hotspot melting zone. Pyroxenite melts to maximum degrees on both sides. Dashed-dotted lines mark the symmetry axis of the model's initial and boundary conditions. (*) For case S2, two different snapshots are shown, one of which (g) corresponds to the snapshot shown in Figure 8i, the other one of which (h) corresponds to that in Figure 8j.

Fig. 7: Plume upwelling rates, temperatures and initial eclogite contents (colors with black denoting $0 \%$ ) for all cases (rows as annotated) in horizontal cross sections at $150 \mathrm{~km}, 250 \mathrm{~km}$ and $350 \mathrm{~km}$ depth (columns as annotated). Black-to-white contours denote mantle potential temperature in $10{ }^{\circ} \mathrm{C}$ increments between $1520{ }^{\circ} \mathrm{C}$ (white) and $1640{ }^{\circ} \mathrm{C}$ (black). Red contours denote plume upwelling rates on a log-scale (spaced by factor $\log _{10}(0.2)$ ). Disk insets (top) schematically show the initial distribution of eclogite, similar to Fig. 4. The black and red crosses (as well as the bull's eyes of the grey-to-black and of the red contours) mark the peak in plume temperature, and the focus of most vigorous upwelling, respectively. Whereas for cases S1 and Z1-Z2, the centers of these bull's eyes fall on top of each other, they are displaced from each other for cases S2 and Z3-Z5. Such a displacement identifies an asymmetry in temperature structure across the ascending plume. For reference, the deep plume stem at the bottom of the box (i.e., $660 \mathrm{~km}$ depth) is centered at $x=3135 \mathrm{~km}$ and $y=1650 \mathrm{~km}$; plate motion is from right to left by rates of $80 \mathrm{~km} / \mathrm{Myr}$.

Fig. 7: continued.

Fig. 8: Geographical distribution of volcanism for all cases. Dark-grey contours show the flux of 671 volcanism with solid contours at $0.1,1$, and $10 \mathrm{~km}^{3} \mathrm{~km}^{-2} \mathrm{Myr}^{-1}$ from outside to inside. Colors 672 display $X_{P X}$ (note the difference in scales for panels (c-d) and (g) compared to the other panels). 673 Insets zoom into the hotspot region (non-shaded and inside the black dashed line). The edge 
674 lengths of the insets is $200 \mathrm{~km}$, corresponding to a zoom factor of 2:1. White arrows mark the

675

676

677

678

679

680

681

682

683

684

685

686

687

688

689

690

691

692

693

694

695

696

697

698

699

700

701

702

703

704

705

706

707

708 model's northern direction. For time-dependent case S2, only one snapshot is fully shown (b), but zooms into the hotspot region of three additional snapshots are also given (h-j). The snapshot shown in (i) corresponds to that in Figure 6g; the snapshot shown in (j) corresponds to that in Figure 6 h. Averages of $X_{P X}$ for each side of the hotspot are reported in Table 3.

Fig. 9: Synthetic seismic shear-wave velocities at $350 \mathrm{~km}$ depth (shades of grey). Shown are horizontal cross-sections through three-dimensional synthetic models computed from the predicted temperatures, densities, and eclogite contents of (a) a thermal plume model (Ballmer et al., 2011), (b-c) cases S1-S2, and (d-h) cases Z1-Z5. In interpolating the three-dimensional model to the cross-section shown, synthetic seismic velocities are averaged over a depth interval of $50 \mathrm{~km}$. The dashed ellipse is analogous to that shown in Fig. 3e, and thus denotes the approximate size and location of the body of low seismic wave speeds imaged by joint seismic tomography (Cheng et al., this volume).

\section{Appendix: Melting, density, and rheology parameterizations}

\section{$\underline{7.1 \text { Melting parameterization }}$}

The solidi versus depth functions, and the rate change in melt fraction per increment of pressure release of eclogite, pyroxenite and peridotite are parameterized using polynomial regressions to experimental data (Yasuda et al., 1994; Hirschmann, 2000; Pertermann and Hirschmann, 2003). We assume the rate of heat consumption by melting is proportional to the latent heat $L=560 \mathrm{~kJ} / \mathrm{kg}$ and melting rate. However, the processes of eclogite melting and subsequent hybridization of the ambient peridotite to form pyroxenite together are assumed to neither consume nor release latent heat. As soon as the volume fraction of melt in a given lithology exceeds a critical porosity (i.e., $\varphi_{C}=0.4 \%$ in peridotite and $\varphi_{C, P Y X}=10 \%$ in pyroxenite), magmas are instantaneously extracted and taken to feed volcanism (cf. McKenzie, 1985; Schmeling, 2006); thereafter, the solid maintains residual porosities of $\varphi_{R}=0.4 \%$ and $\varphi_{R, P Y X}=5 \%$. This treatment is equivalent to assuming that the timescale of melt extraction is much smaller than that of mantle flow (Kelemen et al., 1997). The porosities applied are bracketed by estimates (Yaxley and Green, 1998; Faul, 2001; Stracke et al., 2006).

Compared to that of dry peridotite, the melting temperature of hydrous peridotite is reduced with increasing water content in the liquid $c_{L}$ (i.e., by $43 c_{L} \mathrm{~K} / \mathrm{wt} . \%$ (Katz et al., 2003)). The liquid water concentration decreases during melting as an inverse function of depletion (i.e., extent of previous or ongoing melting) of hydrous peridotite $F_{H P}$ :

$$
c_{L}=\frac{c}{D_{H 2 O}}=\frac{c_{O}}{F_{H P}+D_{H 2 O}\left(1-F_{H P}\right)}
$$


709

710

711

712

713

714

715

716

717 with

$$
\rho=\rho_{O}-\alpha\left(T-T_{O}\right)+\left(\rho_{M}-\rho_{O}\right) \varphi+\Delta \rho_{F}\left(F_{D P} \Phi_{D P}+F_{H P} \Phi_{E C L}\right)+\Delta \rho_{E C L} \Phi_{E C L}
$$$$
\varphi=\varphi_{P Y X} \Phi_{P Y X}+\varphi_{D P} \Phi_{D P}+\varphi_{H P} \Phi_{H P}
$$

718

719

720

721

722

723

724

725

726

727

728

729

730

731

732

733

734

735

736

737

738

739

740 and subscripts PYX, ECL, HP, and DP referring to the components pyroxenite, eclogite, hydrous and dry peridotite, respectively; $\Phi_{X Y}$ is volume fraction of a component; $\varphi_{X Y}$ is porosity in a component; $F_{X Y}$ is depletion of a component; $T$ is temperature; $T_{O}$ is reference temperature; $\rho$ is density; $\rho_{O}$ is reference density; $\alpha$ is thermal expansivity; $\varphi$ is bulk porosity; $\rho_{M}$ is density of melt; $\Delta \rho_{F}$ is density change with depletion; and $\Delta \rho_{E C L}$ is excess density of eclogite. The densities of both dry and hydrated peridotite decrease as depletion increases during progressive melting, since heavy minerals and oxides are preferentially consumed during melting (Schutt and Lesher, 2006). In contrast, we assume the densities of eclogite and pyroxenite to be independent of depletion (due to their relatively small volume fraction and uniform mineralogy, respectively). $\triangle \rho_{E C L}$ was fixed at $220 \mathrm{~kg} / \mathrm{m}^{3}$ in the depth range 300 to $410 \mathrm{~km}$, and $110 \mathrm{~kg} / \mathrm{m}^{3}$ elsewhere (Aoki and Takahashi, 2004). We also ignore the effect of the refractory lithology on bulk density (i.e., by setting $\Delta \rho_{R L} \equiv 0$ ), assuming a negligible intrinsic negative density anomaly of this minor component. As the volume fraction of the refractory component $\Phi_{R L}=\Phi_{E C L, S W}-\Phi_{E C L}$ (except for where eclogite melting has taken place) with $\Phi_{E C L, S W}$ the initial volume fraction of eclogite on the SW side of the plume stem (i.e., a constant for each calculation), $\Delta \rho_{R L}$ also largely trades off with $\triangle \rho_{E C L}$.

\subsection{Rheology parameterization}

We apply a Newtonian rheology to model convection in the mantle. We neglect the stressdependence of mantle viscosity $\eta$, and focus on the effects of composition, temperature and melt. While stress-dependent dislocation creep is relevant for plume-lithosphere interaction in the asthenosphere (Asaadi et al., 2011), stress-independent diffusion creep is thought to be the dominant mechanism of deformation in the lower upper mantle and at the depths of the DEP 
(Karato and $\mathrm{Wu}, 1993$ ). We chose an activation energy of $E^{*}=300 \mathrm{~kJ} / \mathrm{mol}$, which is appropriate for modeling diffusion creep (Karato and Wu, 1993; Hirth, 2002). Finally, we account for the effects of dehydration in olivine (Hirth and Kohlstedt, 1996) and melt retention on rheology (Kohlstedt and Zimmerman, 1996). Whereas melt retention lubricates the mantle, dehydration stiffening during progressive melting is thought to be dominant (Karato, 1986). We parameterize mantle rheology such, that hydrous peridotite stiffens by a factor of $\xi=100$, as it dehydrates from $c=100 \mathrm{ppm}$ to $c=c_{d r y}$ (Hirth and Kohlstedt, 1996). Mantle rheology is instead taken to be insensitive to the abundance of olivine-free (eclogite, pyroxenite) lithologies, since deformation of a fine-scale (i.e., compared to the length-scale of convection) assemblage is predominantly compensated by the weakest lithology (i.e., peridotite) as long as it forms the matrix. Substituting Eq. 1 or Eq. 2 into Eq. 5 thus leaves with a rheology dependent on the depletion in hydrous peridotite $F_{H P}$ and melt content $\varphi$, in addition to the dependence on temperature $T$ and depth $z$ :

$$
\eta=\eta_{m} \exp \left(\frac{E^{*}+\rho_{m} g z V^{*}}{R T}-\frac{E^{*}}{R T_{m}}\right) \frac{\left[\left(c-c_{d r y}\right) \frac{\xi}{\xi-1}\right]^{\Phi_{H P}}}{\exp (\zeta \varphi)}
$$

with $\eta_{m}$ the reference mantle viscosity and all other parameters reported in Table 2 . The effective mantle viscosity of $\eta_{\text {eff }}=1.6 \cdot 10^{19} \mathrm{~Pa} \cdot \mathrm{s}$ defines the minimum viscosity of the asthenosphere in a mantle column well away from the hotspot, typically reached at $\sim 160 \mathrm{~km}$ depth.

\section{Acknowledgements}

M.D.B. and G.I. were supported by NSF-grant EAR-1141938. Calculations were performed on NSF's TeraGrid (XSEDE) using allocation TG-EAR120012, as well as at the Hawaii Open Supercomputing Center. We thank associate editor Mike Poland and two anonymous reviewers for comments that helped to improve the manuscript.

\section{References}

Abouchami, W., Hofmann, A.W., Galer, S.J.G., Frey, F.A., Eisele, J., Feigenson, M., 2005. Lead isotopes reveal bilateral asymmetry and vertical continuity in the Hawaiian mantle plume. Nature. 434, 851-856.

Aoki, I., Takahashi, E., 2004. Density of MORB eclogite in the upper mantle. Phys. Earth Planet. Inter. 143, 129-143.

Asaadi, N., Ribe, N.M., Sobouti, F., 2011. Inferring nonlinear mantle rheology from the shape of the Hawaiian swell. Nature. 473, 501-504.

Ballmer, M.D., Ito, G., van Hunen, J., Tackley, P.J., 2010. Small-scale sublithospheric convection reconciles geochemistry and geochronology of 'Superplume' volcanism in the western and south Pacific. Earth Planet. Sci. Lett. 290, 224-232. 
Ballmer, M.D., Ito, G., van Hunen, J., Tackley, P.J., 2011. Spatial and temporal variability in Hawaiian hotspot volcanism induced by small-scale convection. Nature Geoscience. 4, 457-460.

Ballmer, M.D., Ito, G., Wolfe, C.J., Solomon, S.C., 2013. Double layering of a thermochemichal plume in the upper mantle beneath Hawaii. Earth Planet. Sci. Lett., in press.

Ballmer, M.D., van Hunen, J., Ito, G., Tackley, P.J., Bianco, T.A., 2007. Non-hotspot volcano chains originating from small-scale sublithospheric convection. Geophys. Res. Lett. 34.

Boyet, M., Carlson, R.W., 2005. Nd-142 evidence for early (>4.53 Ga) global differentiation of the silicate Earth. Science. 309, 576-581.

Burke, K., Torsvik, T.H., 2004. Derivation of Large Igneous Provinces of the past 200 million years from long-term heterogeneities in the deep mantle. Earth Planet. Sci. Lett. 227, 531-538.

Castillo, P.R., Natland, J.H., Niu, Y.L., Lonsdale, P.F., 1998. Sr, Nd and Pb isotopic variation along the Pacific-Antarctic risecrest, 53-57 degrees S: Implications for the composition and dynamics of the South Pacific upper mantle. Earth Planet. Sci. Lett. 154, 109-125.

Chauvel, C., Maury, R.C., Blais, S., Lewin, E., Guillou, H., Guille, G., Rossi, P., Gutscher, M.A., 2012. The size of plume heterogeneities constrained by Marquesas isotopic stripes. Geochemistry Geophysics Geosystems. 13, Q07005.

Cheng, C., Allen, R.M., Porritt, R.W., Ballmer, M.D., Seismic constraints on a double-layered asymmetric whole-mantle plume beneath Hawaii, in: R. Carey, D. Weis, M. Poland, (Eds), Hawaiian Volcanism: From Source to Surface, AGU Monograph, this volume.

Crosby, A.G., McKenzie, D., 2009. An analysis of young ocean depth, gravity and global residual topography. Geophys. J. Int. 178, 1198-1219.

Davaille, A., 1999. Simultaneous generation of hotspots and superswells by convection in a heterogeneous planetary mantle. Nature. 402, 756-760.

Dupre, B., Allegre, C.J., 1983. Pb-Sr variation in Indian Ocean basalts and mixing phenomena. Nature. 303, 142-146.

Farnetani, C.G., Hofmann, A.W., 2009. Dynamics and internal structure of a lower mantle plume conduit. Earth Planet. Sci. Lett. 282, 314-322.

Farnetani, C.G., Hofmann, A.W., 2010. Dynamics and internal structure of the Hawaiian plume. Earth Planet. Sci. Lett. 295, 231-240.

Farnetani, C.G., Hofmann, A.W., Class, C., 2012. How double volcanic chains sample geochemical anomalies from the lowermost mantle. Earth Planet. Sci. Lett. 359, 240-247.

Farnetani, C.G., Samuel, H., 2005. Beyond the thermal plume paradigm. Geophys. Res. Lett. 32.

Faul, U., 2001. Melt retention and segregation beneath mid-ocean ridges. Nature. 410, 920-923.

Faul, U.H., Jackson, I., 2005. The seismological signature of temperature and grain size variations in the upper mantle Earth Planet. Sci. Lett. 234, 119-134.

Frey, F.A., Rhodes, J.M., 1993. Intershield geochemical differences among Hawaiian volcanoes - implications for source compositions, melting process and magma ascent paths. Phil. Trans. R. Soc. Lond. A. 342, 121-136.

Greene, A.R., Garcia, M.O., Weis, D., Ito, G., Kuga, M., Robinson, J., Yamasaki, S., 2010. Lowproductivity Hawaiian volcanism between Kaua'i and O'ahu. Geochem. Geophys. Geosyst. 11, Q0AC08.

Griffiths, R.W., Campbell, I.H., 1990. Stirring and Structure In Mantle Starting Plumes. Earth Planet. Sci. Lett. 99, 66-78. 
Hauri, E.H., 1996. Major element variability in the Hawaiian mantle plume. Nature. 382, 415419.

Herzberg, C., 2011. Identification of source lithology in the Hawaiian and Canary Islands: implications for origins. J. Petrol. 52, 113-146.

Herzberg, C., Asimow, P.D., Arndt, N., Niu, Y.L., Lesher, C.M., Fitton, J.G., Cheadle, M.J., Saunders, A.D., 2007. Temperatures in ambient mantle and plumes: constraints from basalts, picrites, and komatiites. Geochem. Geophys. Geosyst. 8, 34.

Hirschmann, M.M., 2000. Mantle solidus: experimental constraints and the effects of peridotite composition. Geochem. Geophys. Geosyst. 1.

Hirschmann, M.M., Stolper, E.M., 1996. A possible role for garnet pyroxenite in the origin of the "garnet signature" in MORB. Contrib. Mineral. Petrol. 124, 185-208.

Hirth, G., 2002. Laboratory constraints on the rheology of the upper mantle. Plastic Deformation of Minerals and Rocks. 51, 97-120.

Hirth, G., Kohlstedt, D.L., 1996. Water in the oceanic upper mantle - Implications for rheology, melt extraction and the evolution of the lithosphere. Earth Planet. Sci. Lett. 144, 93-108.

Hirth, G., Kohlstedt, D.L., Rheology of the upper mantle and mantle wedge: A view from the experimentalists, in: J. Eiler, (Ed), Inside the subduction factory, AGU, Washington, D. C., 2003, pp. 83-105.

Huang, S., Hall, P.S., Jackson, M.G., 2011. Geochemical zoning of volcanic chains associated with Pacific hotspots. Nature Geoscience. 4, 874-878.

Huang, S., Humayun, M., Frey, F.A., 2007. Iron/manganese ratio and manganese content in shield lavas from Ko'olau Volcano, Hawai'i. Geochimica et Cosmochimica Acta. 71, 4557-4569.

Huang, S.C., Frey, F.A., 2005. Recycled oceanic crust in the Hawaiian Plume: evidence from temporal geochemical variations within the Koolau Shield. Contributions to Mineralogy and Petrology. 149, 556-575.

Ishii, M., Tromp, J., 1999. Normal-mode and free-air gravity constraints on lateral variations in velocity and density of Earth's mantle. Science. 285, 1231-1235.

Jackson, E.D., Silver, E.A., Dalrymple, G.B., 1972. Hawaiian-Emperor chain and its relation to Cenozoic circumpacific tectonics. Geol. Soc. Amer. Bull. 83, 601-618.

Jackson, M.G., Weis, D., Huang, S., 2012. Major element variations in Hawaiian shield lavas: Source features and perspectives from global ocean island basalt (OIB) systematics. Geochem. Geophys. Geosyst., Q09009.

Karato, S., 1986. Does partial melting reduce the creep strength of the upper mantle. Nature. 319 , 309-310.

Karato, S., Wu, P., 1993. Rheology of the upper mantle - a synthesis. Science. 260, 771-778.

Katz, R.F., Rudge, J.F., 2011. The energetics of melting fertile heterogeneities within the depleted mantle. Geochemistry Geophysics Geosystems. 12.

Katz, R.F., Spiegelman, M., Langmuir, C.H., 2003. A new parameterization of hydrous mantle melting. Geochem. Geophys. Geosyst. 4, 1073.

Kelemen, P.B., Hirth, G., Shimizu, N., Spiegelman, M., Dick, H.J.B., 1997. A Review Of Melt Migration Processes In the Adiabatically Upwelling Mantle Beneath Oceanic Spreading Ridges. Philosophical Transactions Of the Royal Society Of London Series a Mathematicalphysical and Engineering Sciences. 355, 283-318.

Kohlstedt, D.L., Zimmerman, M.E., 1996. Rheology of partially molten mantle rocks. Ann. Rev. Earth Planet. Sci. 24, 41-62. 
Konter, J.G., Hanan, B.B., Blichert-Toft, J., Koppers, A.A.P., Plank, T., Staudigel, H., 2008. One hundred million years of mantle geochemical history suggest the retiring of mantle plumes is premature. Earth Planet. Sci. Lett. 275, 285-295.

Kumagai, I., Davaille, A., Kurita, K., Stutzmann, E., 2008. Mantle plumes: Thin, fat, successful, or failing? Constraints to explain hot spot volcanism through time and space. Geophys. Res. Lett. 35, L16301.

Kurz, M.D., Kenna, T.C., Lassiter, J.C., DePaolo, D.J., 1996. Helium isotopic evolution of Mauna Kea Volcano: First results from the 1-km drill core. Journal of Geophysical Research-Solid Earth. 101, 11781-11791.

Labrosse, S., Hernlund, J.W., Coltice, N., 2007. A crystallizing dense magma ocean at the base of the Earth's mantle. Nature. 450, 866-869.

Lin, S.C., van Keken, P.E., 2005. Multiple volcanic episodes of flood basalts caused by thermochemical mantle plumes. Nature. 436, 250-252.

Mallik, A., Dasgupta, R., 2012. Reaction between MORB-eclogite derived melts and fertile peridotite and generation of ocean island basalts. Earth Planet. Sci. Lett. 329, 97-108.

Masters, G., Laske, G., Bolton, H., Dziewonski, A., The relative behavior of shear velocity, bulk sound speed, and compressional velocity in the mantle: Implications for chemical and thermal structure., in: S. Karato, A.M. Forte, R.C. Liebermann, G. Masters, L. Stixrude, (Eds), Geophysical Monograph on Mineral Physics and Seismic Tomography fom the atomic to the global scale, Americal Geophysical Union, 2000, pp. 63-87.

McKenzie, D., 1985. The Extraction Of Magma From the Crust and Mantle. Earth Planet. Sci. Lett. 74, 81-91.

Moresi, L., Zhong, S., Gurnis, M., 1996. The accuracy of finite element solutions of Stokes' flow with strongly varying viscosity. Phys. Earth Planet. Int. 97, 83-94.

Morgan, W.J., 1972. Plate motions and deep mantle convection. Geol. Soc. Am. Memoir. 132, 722.

Mosca, I., Cobden, L., Deuss, A., Ritsema, J., Trampert, J., 2012. Seismic and mineralogical structures of the lower mantle from probabilistic tomography. J. Geophys. Res. 117, B06304.

Payne, J.A., Jackson, M.G., Hall, P.S., 2013. Parallel volcano trends and geochemical asymmetry of the Society Islands hotspot track. Geology. 41, 19-22.

Pertermann, M., Hirschmann, M.M., 2003. Partial melting experiments on a MORB-like pyroxenite between 2 and $3 \mathrm{GPa}$ : Constraints on the presence of pyroxenite in basalt source regions from solidus location and melting rate. J. Geophys. Res. 108, 2125.

Phipps Morgan, J., 2001. Thermodynamics of pressure release melting of a veined plum pudding mantle. Geochem. Geophys. Geosyst. 2, 2000GC000049.

Pietruszka, A.J., Norman, M.D., Garcia, M.O., Marske, J.P., Burns, D.H., 2013. Chemical heterogeneity in the Hawaiian mantle plume from the alteration and dehydration of recycled oceanic crust. Earth Planet. Sci. Lett. 361, 298-309.

Putirka, K., Ryerson, F.J., Perfit, M., Ridley, W.I., 2011. Mineralogy and Composition of the Oceanic Mantle. Journal of Petrology. 52, 279-313.

Ribe, N.M., Christensen, U.R., 1994. Three-dimensional modeling of plume-lithosphere interaction. J. Geophys. Res. 99, 669-682.

Ribe, N.M., Christensen, U.R., 1999. The dynamical origin of Hawaiian volcanism. Earth Planet. Sci. Lett. 171, 517-531. 
Robinson, J.E., Eakins, B.W., 2006. Calculated volumes of individual shield volcanoes at the young end of the Hawaiian Ridge. J. Volcanology Geothermal Res. 151, 309-317.

Rychert, C.A., Laske, G., Harmon, N., Shearer, P.M., 2013. Seismic imaging of melt in a displaced Hawaiian plume. Nature Geosci. 6, 657-660.

Schmeling, H., 2006. A model of episodic melt extraction for plumes. J. Geophys. Res. 111, B03202, doi:03210.01029/02004JB003423.

Schutt, D.L., Lesher, C.E., 2006. Effects of melt depletion on the density and seismic velocity of garnet and spinel lherzolite. J. Geophys. Res. 111, B05401.

Sinton, J., Eason, D.E., Tardona, M., Pyle, D.G., van der Zander, I., Guillou, H., Flinders, A., Clague, D.A., Mahoney, J.J., in review. Ka'ena Volcano - a precursor volcano of the island of O`ahu, Hawai'i.

Sleep, N.H., 1990. Hotspots and mantle plumes - some phenomenology. J. Geophys. Res. 95, 6715-6736.

Sobolev, A.V., Hofmann, A.W., Kuzmin, D.V., Yaxley, G.M., Arndt, N.T., Chung, S.L., Danyushevsky, L.V., Elliott, T., Frey, F.A., Garcia, M.O., Gurenko, A.A., Kamenetsky, V.S., Kerr, A.C., Krivolutskaya, N.A., Matvienkov, V.V., Nikogosian, I.K., Rocholl, A., Sigurdsson, I.A., Sushchevskaya, N.M., Teklay, M., 2007. The amount of recycled crust in sources of mantle-derived melts. Science. 316, 412-417.

Sobolev, A.V., Hofmann, A.W., Sobolev, S.V., Nikogosian, I.K., 2005. An olivine-free mantle source of Hawaiian shield basalts. Nature. 434, 590-597.

Sobolev, S.V., Sobolev, A.V., Kuzmin, D.V., Krivolutskaya, N.A., Petrunin, A.G., Arndt, N.T., Radko, V.A., Vasiliev, Y.R., 2011. Linking mantle plumes, large igneous provinces and environmental catastrophes. Nature. 477, 312-316.

Steinberger, B., Antretter, M., 2006. Conduit diameter and buoyant rising speed of mantle plumes: Implications for the motion of hot spots and shape of plume conduits. Geochemistry Geophysics Geosystems. 7, Q11018.

Steinberger, B., Torsvik, T.H., 2012. A geodynamic model of plumes from the margins of Large Low Shear Velocity Provinces. Geochemistry Geophysics Geosystems. 13, Q01w09.

Stracke, A., Bourdon, B., McKenzie, D., 2006. Melt extraction in the Earth's mantle: Constraints from U-Th-Pa-Ra studies in oceanic basalts. Earth Planet. Sci. Lett. 244, 97-112.

Stracke, A., Snow, J.E., Hellebrand, E., von der Handt, A., Bourdon, B., Birbaum, K., Günther, D., 2011. Abyssal peridotite Hf isotopes identify extreme mantle depletion. Earth Planet. Sci. Lett. 308, 359-368.

Torsvik, T.H., Burke, K., Steinberger, B., Webb, S.J., Ashwal, L.D., 2010. Diamonds sampled by plumes from the core-mantle boundary. Nature. 466, 352-U100.

Torsvik, T.H., Smethurst, M.A., Burke, K., Steinberger, B., 2006. Large igneous provinces generated from the margins of the large low-velocity provinces in the deep mantle. Geophys. J. Int., doi:10.1111/j.1365-1246X.2006.03158.x.

van Ark, E., Lin, J., 2004. Time variation in igneous volume flux of the Hawaii-Emperor hot spot seamount chain. J. Geophys. Res. 109, B11401

Vidal, V., Bonneville, A., 2004. Variations of the Hawaiian hot spot activity revealed by variations in the magma production rate. J. Geophys. Res. 109, B03104.

Weis, D., Garcia, M.O., Rhodes, J.M., Jellinek, M., Scoates, J.S., 2011. Role of the deep mantle in generating the compositional asymmetry of the Hawaiian mantle plume. Nature Geosci. 4, 831-838. 
Wen, L., 2006. A compositional anomaly at the Earth's core-mantle boundary as an anchor to the relatively slowly moving surface hotspots and as source to the DUPAL anomaly. Earth Planet. Sci. Lett. 246, 138-148.

Wen, L.X., Silver, P., James, D., Kuehnel, R., 2001. Seismic evidence for a thermo-chemical boundary at the base of the Earth's mantle. Earth Planet. Sci. Lett. 189, 141-153.

Wessel, P., 1993. Observational constraints on models of the Hawaiian hot-spot swell. J. Geophys. Res. 98, 16095-16104.

Wolfe, C.J., Solomon, S.C., Laske, G., Collins, J.A., Detrick, R.S., Orcutt, J.A., Bercovici, D., Hauri, E.H., 2009. Mantle Shear-Wave Velocity Structure Beneath the Hawaiian Hot Spot. Science. 326, 1388-1390.

Wolfe, C.J., Solomon, S.C., Laske, G., Collins, J.A., Detrick, R.S., Orcutt, J.A., Bercovici, D., Hauri, E.H., 2011. Mantle P-wave Velocity Structure beneath the Hawaiian Hotspot. Earth Plan. Sci. Lett., doi:10.1016/j.eps1.2011.1001.1004.

Workman, R.K., Hart, S.R., Jackson, M., Regelous, M., Farley, K.A., Blusztajn, J., Kurz, M., Staudigel, H., 2004. Recycled metasomatized lithosphere as the origin of the enriched mantle II (EM2) end-member: Evidence from the Samoan volcanic chain. Geochemistry Geophysics Geosystems. 5.

Xu, G., Huang, S., Frey, F.A., Blichert-Toft, J., Abouchami, W., Clague, D.A., Cousens, B., Moore, J.G., Beeson, M.H., in press. The Distribution of Geochemical Heterogeneities in the Source of Hawaiian Shield Lavas as Revealed by a Transect Across the Strike of the Loa and Kea Spatial Trends: East Molokai to West Molokai to Penguin Bank. Geochem. Cosmochem. Acta.

Xu, W., Lithgow-Bertelloni, C., Stixrude, L., Ritsema, J., 2008. The effect of bulk composition and temperature on mantle seismic structure. Earth Planet. Sci. Lett. 275, 70-79.

Yasuda, A., Fujii, T., Kurita, K., 1994. Melting phase-relations of an anhydrous midocean ridge basalt from 3 to $20 \mathrm{GPa}$ - implications for the behavior of subducted oceanic-crust in the mantle. J. Geophys. Res. 99, 9401-9414.

Yaxley, G.M., Green, D.H., 1998. Reactions between eclogite and peridotite: Mantle refertilisation by subduction of oceanic crust. Schweizerische Mineralogische und Petrographische Mitteilungen. 78, 243-255.

Zou, H.B., 1998. Trace element fractionation during modal and nonmodal dynamic melting and open-system melting: A mathematical treatment. Geochem. Cosmochem. Acta. 62, 19371945. 


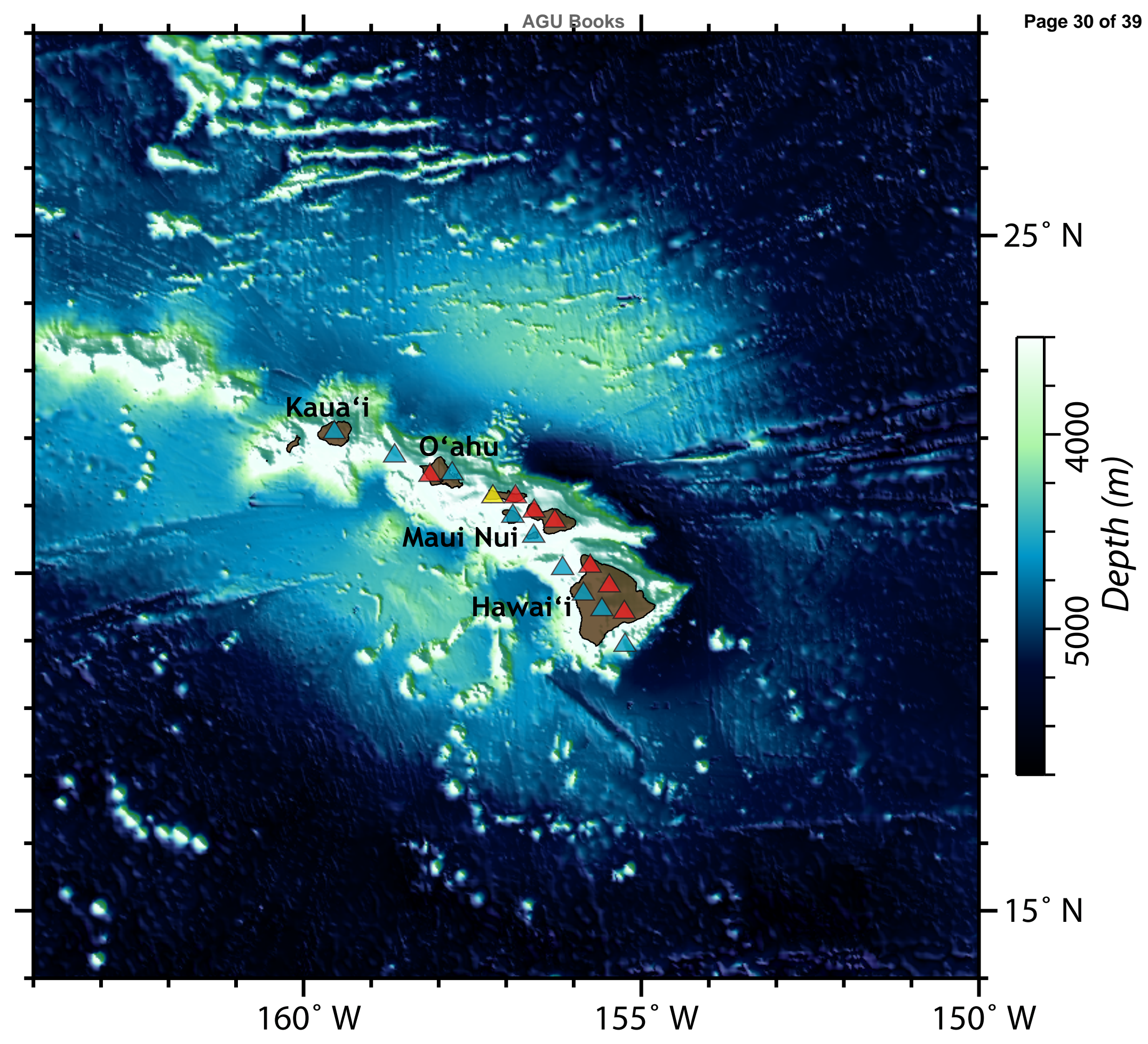




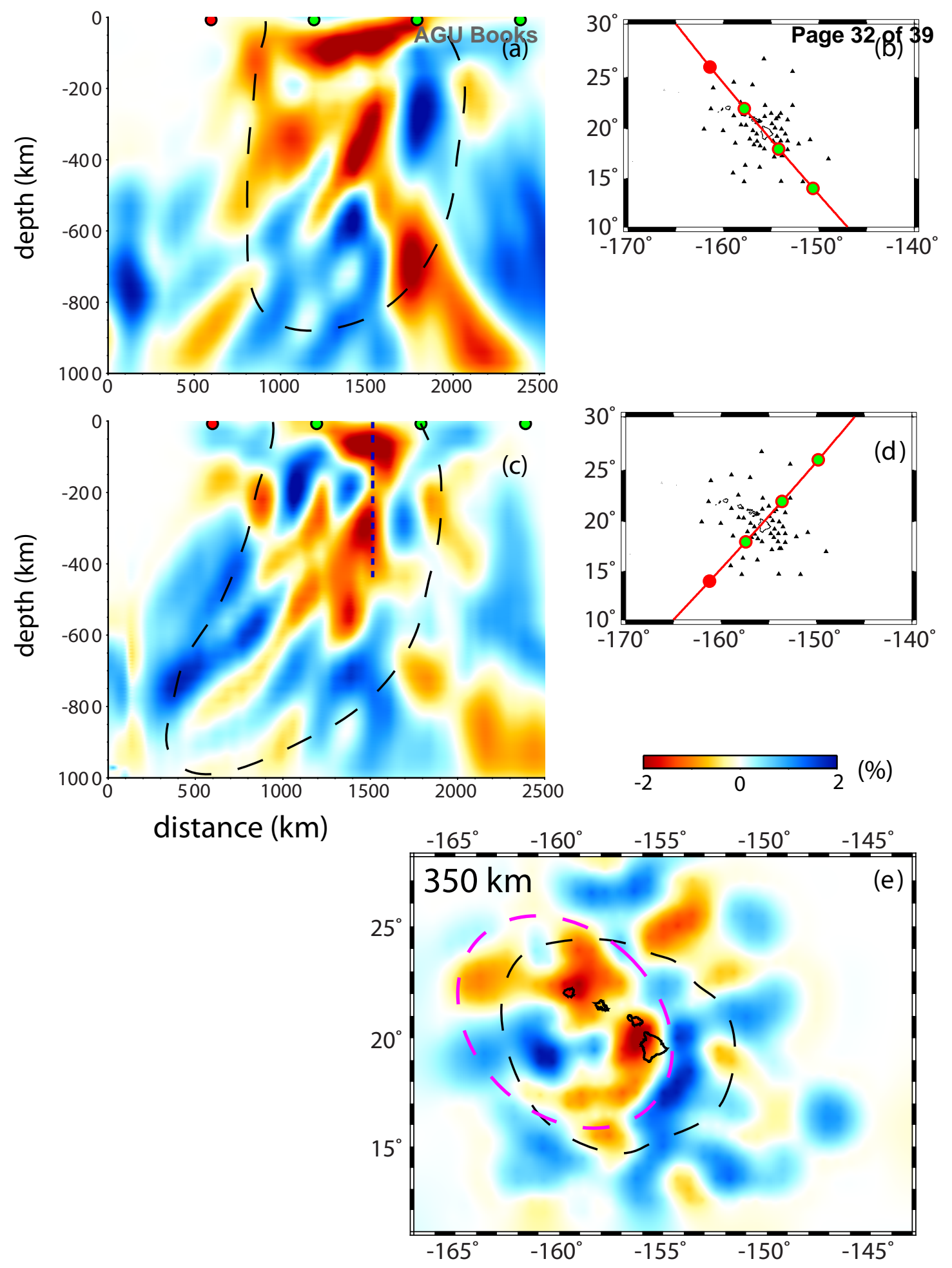









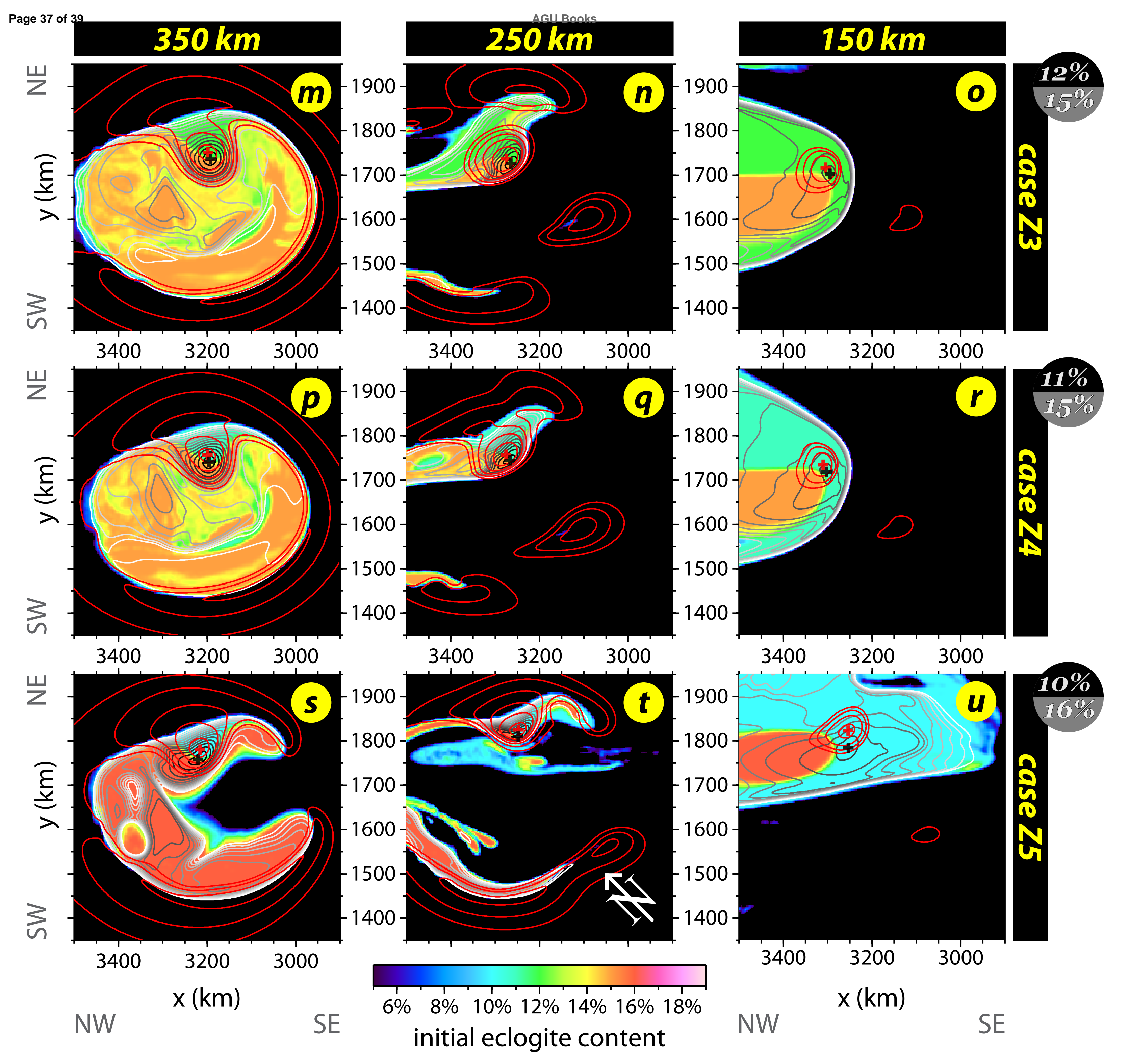




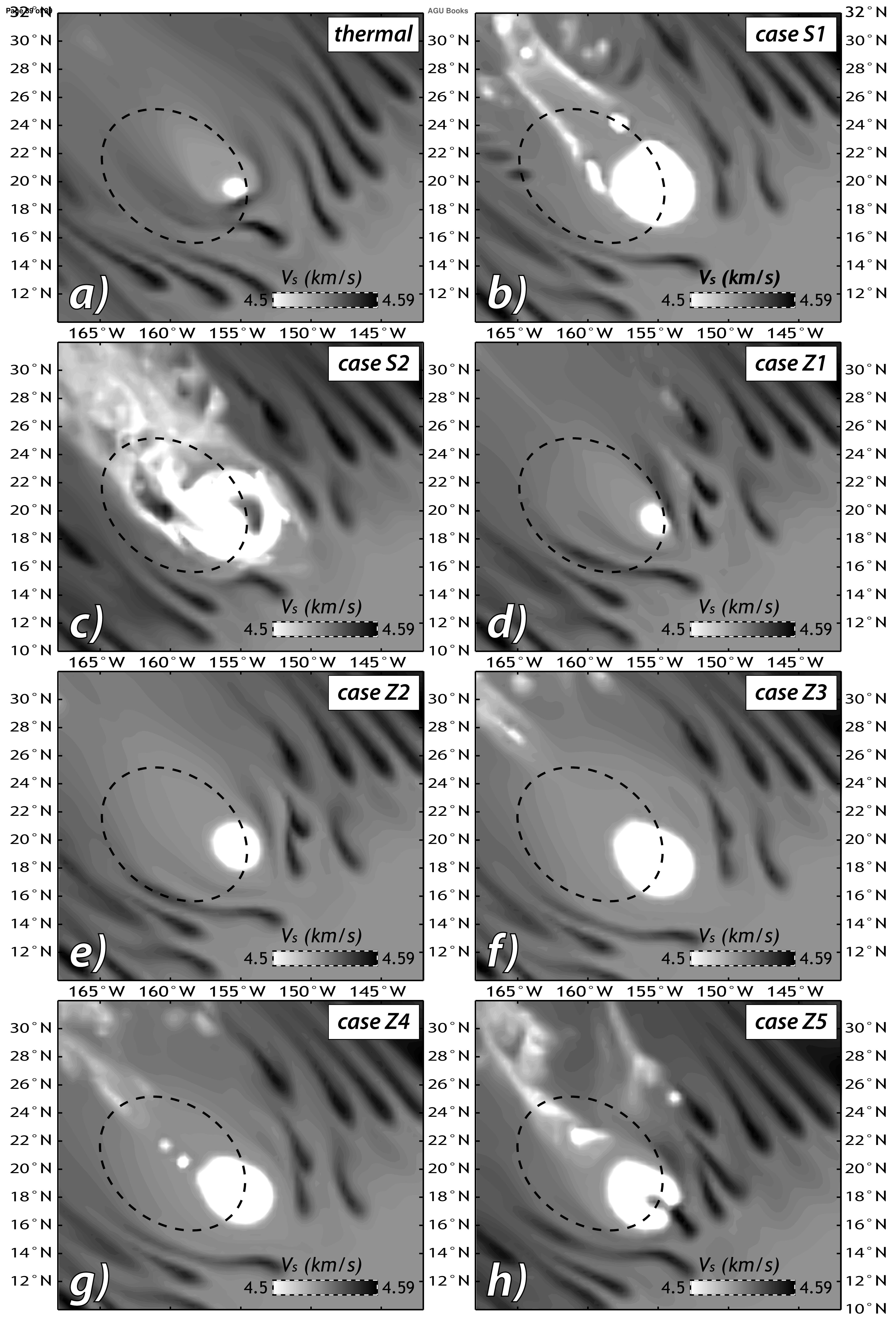

